\title{
Volume for pollution dispersion: London's atmospheric boundary layer during ClearfLo observed with two ground-based lidar types
}

Article

Accepted Version

Creative Commons: Attribution-Noncommercial-No Derivative Works 4.0

Kotthaus, S., Halios, C. H., Barlow, J. F. and Grimmond, C. S. B. (2018) Volume for pollution dispersion: London's atmospheric boundary layer during ClearfLo observed with two ground-based lidar types. Atmospheric Environment, 190. pp. 401-414. ISSN 1352-2310 doi:

https://doi.org/10.1016/j.atmosenv.2018.06.042 Available at https://centaur.reading.ac.uk/77953/

It is advisable to refer to the publisher's version if you intend to cite from the work. See Guidance on citing.

To link to this article DOI: http://dx.doi.org/10.1016/j.atmosenv.2018.06.042

Publisher: Elsevier

All outputs in CentAUR are protected by Intellectual Property Rights law, including copyright law. Copyright and IPR is retained by the creators or other copyright holders. Terms and conditions for use of this material are defined in the End User Agreement. 


\section{www.reading.ac.uk/centaur}

\section{CentAUR}

Central Archive at the University of Reading

Reading's research outputs online 
Volume for pollution dispersion: London's atmospheric boundary layer during ClearfLo observed with two ground-based lidar types

\title{
Simone Kotthaus, Christos H. Halios, Janet F. Barlow, and C.S.B. Grimmond
}

\author{
Contact: s.kotthaus@reading.ac.uk, c.s.grimmond@reading.ac.uk
}

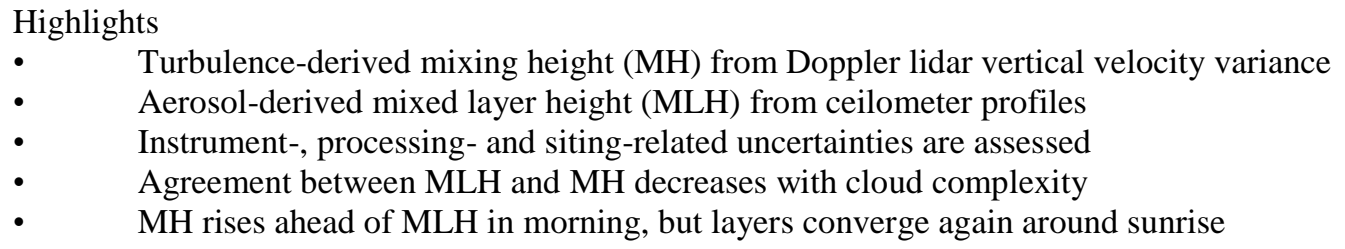

\begin{abstract}
In urban areas with high air pollution emissions, the boundary layer volume within which gases and particles are diluted is critical to air quality impacts. With advances in ground-based remote sensing technologies and data processing algorithms, observations of layers forming the atmospheric boundary layer $(\mathrm{ABL})$ are becoming increasingly available at high temporal resolution. Here, mixing height $(\mathrm{MH})$ estimates determined from turbulence measurements of Doppler lidars and aerosol derived mixed layer height (MLH) based on automatic lidar and ceilometer (ALC) observations within the centre of London are assessed. While MH uncertainty increases with shorter duration of vertical stare sampling within the Doppler lidar scan pattern, instrument-related noise of the ALC may result
\end{abstract}

in large MLH errors due to the challenging task of layer attribution. However, when long time series are assessed most of the algorithm- and instrument-related uncertainties average out and therefore become less critical to overall climatological analyses. Systematic differences occur in nocturnal MH from two nearby (3-4 km) sites but MLH estimates at both sites generally agree with MH obtained at the denser urban setting. During daytime, most spatial variations in ABL structure induced by synoptic conditions or land cover heterogeneity at this scale do not exceed measurement uncertainty. Agreement between MH and MLH is clearly affected by ABL aerosol content and cloud 28 conditions. Discrepancies increase with cloud complexity. On average, MH rises ahead of MLH during the morning growth period and peaks earlier in the day. There is a faster afternoon decay of MLH so that MLH and MH converge again around sunset and often have similar nocturnal values. Results demonstrate that turbulence-derived MH and aerosol-derived MLH should not be used inter32 changeably for purposes of model evaluation, interpretation of surface air quality observations or 33 initialisation of chemical transport models.

Keywords: urban boundary layer; aerosol dispersion volume; mixed layer height; mixing height; ground-based remote sensing; clouds

\section{Introduction}

The structure and evolution of the atmospheric boundary layer (ABL) is important to measure accurately, as it can strongly affect the concentration of pollutants near the surface (e.g. Sujatha et al., 2016). A better understanding of the various layers that compose the $\mathrm{ABL}$ is critical to interpreting air quality observations (e.g. Curci et al., 2015; Tang et al., 2016), modelling atmospheric composition (e.g. Warren et al., 2018), and numerical weather prediction (e.g. Wouters et al., 2013). Given the link to human health (Lelieveld et al., 2015) and visibility (Haeffelin et al., 2016), improved ABL process description has significant economic implications.

Given many people are exposed to urban weather and air quality conditions, cities are of interest. Buildings and anthropogenic activities modify atmospheric mixing through the increase in roughness, augmented emission of heat and reduced evapotranspiration rates. Here, ABL dynamics are investigated in a dense European city centre (London, UK) which has been the focus of several measurement and modelling studies (e.g. REPARTEE, Harrison et al., 2012; ACTUAL, Barlow et al. 2015; ClearfLo, Bohnenstengel et al., 2015). The boundary layer structure of London has been studied using SODAR (Spanton and Williams, 1988), Doppler lidar (Barlow et al., 2011, 2015; Halios and Barlow, 2017) or ceilometer observations (Kotthaus and Grimmond, 2018a), in-situ measurements at elevated heights (Wood et al., 2010), and meso-scale modelling (e.g. Bohnenstengel et al., 2011).

While ABL estimates from radiosonde ascents have been used widely (Seibert, 2000), they are usually infrequent and rarely done for central urban settings (Piringer et al., 2007). Profiling by ground-based atmospheric remote sensing (e.g. Doppler lidar or Automatic Lidars and Ceilometers, ALC) again provides more information on ABL structure at high temporal resolution in urban areas (Wiegner et al., 2006). As they utilise eye-safe lasers, cause no sound pollution and have low maintenance requirements, both Doppler lidars and ALC are highly suitable for operation in densely populated places. While Doppler lidars can record both the three-dimensional wind field and attenuated backscatter, 
ALC are designed to detect clouds based on the aerosol attenuated backscatter profiles. Both lidar types use atmospheric aerosol as a tracer (Barlow, 2014), but applying different indicators to track the structure of the ABL results in a slightly different representation (Barlow et al., 2011). While turbulence fields derived from high-resolution sampling of the wind profile allow the instantaneous state of dynamic mixing to be explored, aerosol attenuated backscatter fields form in response to these turbulent processes and represent the current state of aerosol vertical distribution (Träumner et al., 2011). Thus, the turbulence-derived mixing height (MH) may differ from the aerosol-derived mixed layer height (MLH). Hygroscopic aerosol growth processes modified by the vertical distribution of humidity can affect the observed attenuated backscatter which may influence MLH results (Gibert et al., 2007).

Previously, turbulence-derived MH and aerosol-derived MLH have been compared for short campaigns with estimates based on vertical velocity variance and attenuated backscatter from a Doppler lidar (e.g. Barlow et al., 2011; Pearson et al., 2010; Träumner et al., 2011). Schween et al. (2014) analyse a year of MH from Doppler turbulence observations with MLH from ALC measurements. However, a coherent relation between the turbulence- and aerosol-derived layer estimates does not arise. While all studies find that MH can be both greater or smaller than MLH at times, Schween et al. (2014) conclude that MLH clearly exceeds MH on average during all times of the day and all seasons, while Barlow et al. (2011) found that MH grows earlier in the morning and also decays earlier in the evening, so that it exceeds and falls below MLH during these times respectively. Such time lag is consistent with the discussion of Träumner et al. (2011) who state that MH captures the state of the turbulence at a given time while MLH rather represents the concept of past (or "fossil") turbulence portrayed by ABL aerosol and moisture.

Measurement location and synoptic settings may impact the conclusions drawn. The MLH and MH comparison for clear-sky days from different locations in England, France and Germany presented by Träumner et al. (2011) vary considerably. Barlow et al. (2011) find nocturnal agreement to decrease and daytime values to become more similar for cloud-free periods in central London, whereas Schween et al. (2014) see no clear effect when applying a cloud filter in rural Germany. With the variety of ABL conditions (Harvey et al., 2015; Kotthaus and Grimmond, 2018a), the synoptic background is important for atmospheric stratification and hence both turbulent structures and aerosol distributions should be considered in a detailed comparison of MH and MLH measurements.

Instrument details (e.g. laser power, optical overlap), data processing, and choice of detection algorithms are likely to be important. For all lidar sensors the optical overlap affects the minimum height at which a layer can be detected. Highpower sensors often have a longer blind zone where shallow layers might be missed. The overlap can be corrected to a certain degree, but careful processing might be required (Hervo et al., 2016). Kotthaus et al. (2016) demonstrate that hardware configuration, firmware version and data processing can impact the attenuated backscatter observed with Vaisala CL31 ceilometers. Its predecessor (Vaisala CT25K) used by Schween et al. (2014) has similar issues, which if not addressed carefully can lead to increased MLH uncertainties. The method applied to determine MLH from attenuated backscatter severely impacts results (e.g. Geiß et al., 2017). While the various methods mostly agree with respect to the initial detection of significant layers, the layer attribution task is the main challenge (Haeffelin et al., 2012). A robust way of deriving $\mathrm{MH}$ is to use a simple threshold of vertical velocity variance or standard deviation (Träumner et al., 2011). However, scan pattern and processing algorithm (Bonin et al., 2017) and the choice of threshold (Schween et al., 2014) can all affect the final MH estimate.

The objectives of this paper are to quantify the difference between the turbulence-derived $\mathrm{MH}$ and aerosol-derived MLH obtained after careful quality control using advanced detection algorithms (Sect. 2). Comparing observations taken at several sites in central London (Sect. 3), implications of instrument-related aspects and spatial displacement are analysed first for both ALC and Doppler lidar to estimate the uncertainty inherent in the MLH and MH results, respectively. This provides the context for the comparison of MLH and MH under different ABL conditions. Conclusions drawn (Sect. 4) have implications for any measurement or modelling study concerned with turbulent mixing within the $\mathrm{ABL}$.

\section{Study area}

This study is conducted in central London, one of the largest European cities $\left(1572 \mathrm{~km}^{2}\right)$ with a population of $8.8 \mathrm{~m}$ in 2016 (ONS, 2017). Urban effects such as increased surface roughness (e.g. Kent et al., 2017), anthropogenic heat emissions (e.g. Bohnenstengel et al., 2014; Gabey et al., 2018; Lindberg et al., 2013), reduced moisture availability (e.g. Ward et al., 2015) and large heat storage (e.g. Sun et al., 2017) clearly affect the surface energy balance (Kotthaus and Grimmond, 2014) and boundary layer dynamics (Barlow et al., 2015) in London. Air quality is a major concern in this dense urban environment (e.g. Bohnenstengel et al., 2015) where pollution from both long-range transport and local emissions (e.g. Visser et al., 2015) cause severe health issues and even impact mortality (e.g. Atkinson et al., 2016).

\section{Instrumentation and processing}

Two heterodyne, pulsed, scanning Doppler lidars (Stream Line, HALO Photonics) and two ALC (CL31, Vaisala) are used to derive MH and MLH, respectively. Differences in sensor height (Table 2) are accounted for as all analysis is performed in $\mathrm{m}$ above ground level (agl). 
The $1.5 \mu \mathrm{m}$ wavelength Doppler lidars (HALO-1 and HALO-2) have a pulse repetition frequency of $10 \mathrm{kHz}$ and a sampling frequency of $50 \mathrm{MHz}$. Integrated signals were output every $3.6 \mathrm{~s}$ (sampling rate of $0.278 \mathrm{~Hz}$ ) at a range resolution of $30 \mathrm{~m}$ (HALO-1) or $18 \mathrm{~m}$ (HALO-2). Returns were spurious in the first three range gates of both due to the geometry of the transmitter and receiver so here analyses start at the fourth range gate (mid-point $105 \mathrm{~m}$ above the HALO-1 and $63 \mathrm{~m}$ above the HALO-2). Empirical correction factors (obtained based on communication with the manufacturer) are applied to lidar attenuated backscatter to account for the focal length of HALO-1 being set to $500 \mathrm{~m}$, however, no corrections are required for HALO-2 which was operated with a focal length set to infinity (Hirsikko et al., 2014). No focus correction is needed for the Doppler velocities, which are used to derive MH in this paper. Different scan patterns (SP, cycle length indicated by subscript; Table 1, Table 2) were used depending on objectives. In "vertical stare mode" the beam points upwards permitting vertical velocity variance to be measured from which mixing height is calculated.

Table 1: Doppler lidar scan patterns (SP) by cycle length including a combination of vertical stare and scanning modes (Doppler Beam Swinging (DBS), Range Height Indicator (RHI) and non-stare user defined (UD)) with respective duration [s]. For $\mathrm{SP}_{3600}$, the $1^{\text {st }}-3^{\text {rd }}$ stare and scan modes are repeated once.

\begin{tabular}{lllll} 
Scan pattern & $\mathrm{SP}_{120}$ & $\mathrm{SP}_{347}$ & $\mathrm{SP}_{981}$ & $\mathrm{SP}_{3600}$ \\
\hline Cycle length & 120 & 347 & 981 & 3600 \\
$1^{\text {st }}$ vertical stare & 99 & 310 & 150 & 50 \\
$1^{\text {st }}$ scan mode & $21(\mathrm{DBS})$ & $37(\mathrm{DBS})$ & $153(\mathrm{RHI})+36(\mathrm{DBS})$ & 40 (UD) \\
$2^{\text {nd }}$ vertical stare & & & 150 & 210 \\
$2^{\text {nd }}$ scan mode & & & $492(\mathrm{UD})$ & $500(\mathrm{UD})$ \\
$3^{\text {rd }}$ vertical stare & & & 700 \\
$3^{\text {rd }}$ scan mode & & & $500(\mathrm{UD})$ \\
$4^{\text {th }}$ vertical stare & & & 700 \\
$4^{\text {th }}$ scan mode & & & $500(\mathrm{UD})$ \\
$5^{\text {th }}$ vertical stare & & & 400
\end{tabular}

Data with low signal to noise ratio (SNR $<0.019952$ or $-17 \mathrm{~dB}$ ) are removed to maintain errors in single velocity estimates at $0.15 \mathrm{~m} \mathrm{~s}^{-1}$ or less (Lane et al. 2013). A moving average filter is applied to increase SNR in a similar way to the ALC sensor data, to allow fair comparison of the instruments. Vertical velocity variance $\left(\sigma_{\mathrm{w}}^{2}\right)$ at each gate height is calculated for a symmetric sliding window of $3600 \mathrm{~s}$. An unweighted, symmetric moving average of $90 \mathrm{~m}$ (either 3 or 5 range gates) is applied to the vertical profile of $\sigma_{\mathrm{w}}^{2}$. This procedure is repeated every second, giving smoothed vertical profiles at $1 \mathrm{~s}$ resolution starting $1800 \mathrm{~s}$ after the beginning and ending $1800 \mathrm{~s}$ before the end of each $24 \mathrm{~h}$ daily period. For each smoothed vertical profile of $\sigma_{\mathrm{w}}^{2} \mathrm{MH}$ is calculated as the height up to which $\sigma_{\mathrm{w}}^{2}>0.1 \mathrm{~m}^{2} \mathrm{~s}^{-2}$ (Barlow et al., 2011; Halios and Barlow, 2017). MH is given by the 60 min mean between sunrise and sunset, and 30 min at night. The different averaging periods aim to capture the longer turbulence scales during day and possible stationarity issues at night (Stull, 1988). When MH falls below the minimum detection limit of the Doppler lidar, its value is set to the respective lowest possible value.

Finally, a quality control step removes spurious outliers. Block-averaged $\mathrm{MH}$ is filtered using the relative deviation of mean $\left(M_{\text {mean }}(t)\right)$ and median $\mathrm{MH}\left(\mathrm{MH}_{\text {median }}(t)\right)$ within the block average at time step $t$ :

$$
\left|\frac{M H_{\text {mean }}(t)-M H_{\text {median }}(t)}{M H_{\text {mean }}(t)}\right|>0.2
$$

and the temporal variability between successive time steps $t-1, t$ and $t+1$ :

$\left[\frac{M H_{\text {median }}(t)-\frac{M H_{\text {median }}(t-1)+M H_{\text {median }}(t+1)}{2}}{M H_{\text {median }}(t)}\right]>0.5$

MH values that meet both criteria at time $t$ are excluded from analysis. These filters remove overall $15 \%$ of the Doppler lidar MH data (24\% for HALO-1 with $\mathrm{SP}_{3600}, 19 \%$ for HALO-2 with $\mathrm{SP}_{120}$ and 13-14\% otherwise).

The commonly deployed Vaisala CL31 ALC sensor operates at a wavelength of $905 \pm 10 \mathrm{~nm}$. Its single-lens design gives a region of incomplete optical overlap that extends to a range of $70 \mathrm{~m}$ and its effect is entirely corrected for by internal processing. Attenuated backscatter and cloud base height $(\mathrm{CBH})$ are recorded at a resolution of $15 \mathrm{~s}$ and $10 \mathrm{~m}$ with the $\mathrm{H} 2=$ on setting as recommended by the manufacturer (Kotthaus et al., 2016). Observations collected by two CL31 of hardware generation 321 (here labelled CL31-C and CL31-D, Table 2) are operated at four sites in central London (Table 2, Figure 1). Given instrument-related artefacts can significantly impact the quality of attenuated backscatter recorded, background effects and near-range artefacts are corrected (Kotthaus et al., 2016; Kotthaus and Grimmond, 2018a). SNR is increased by applying a smoothing average over $25 \mathrm{~min}$ and $110 \mathrm{~m}$ and data with low SNR are filtered out before applying the "CABAM" algorithm to detect MLH (Kotthaus and Grimmond, 2018a). CABAM uses a series of decision criteria to track MLH based on strong vertical gradients in attenuated backscatter. It further classifies the ABL according to cloud cover and cloud type in relation to MLH. The CABAM algorithm has been successfully evaluated against thermodynamic indicators of the ABL height (Kotthaus and Grimmond, 2018a). MLH 
detection is restricted to the lowest $3 \mathrm{~km}$ of the atmosphere, given the ABL over London is always clearly below this limit. Attenuated backscatter from CL31 can be used for MLH detection up from the first range gate and the lowest detectable layer is $50 \mathrm{~m}$ above the sensor with the approach applied here.

The CABAM detection algorithm operates at the attenuated backscatter recorded resolution. After the automatic detection and layer attribution procedure, results are block-averaged to $15 \mathrm{~min}$ resolution, based on time ending. In addition to the entirely automatic detection results obtained with CABAM, Kotthaus and Grimmond (2018a) perform a supervised MLH detection based on this algorithm. While the two estimates generally agree well regarding their longterm climatology, differences can be large for individual days. Here, supervised CABAM results obtained for CL31-C (MLH_SCL31-C) are considered the most reliable MLH estimate and automatic CABAM results for both CL31-C and CL31-D are included in the analysis to indicate uncertainty in derived MLH that may arise from errors in automatic layer attribution, instrument-related differences in the observed attenuated backscatter profiles and/or spatial displacement.

The Vaisala CBH algorithm applies dynamic temporal averaging to detect up to three cloud layers at the set resolution. However, no details are available for this proprietary method. The probed area at $2000 \mathrm{~m}$ is about $2 \mathrm{~m}^{2}$ given the beam divergence of the CL31 ( $\pm 0.4 \mathrm{mrad})$. To analyse a large spatial extent, the $1^{\text {st }}$ percentile of CBH reported in a $30 \mathrm{~min}$ moving window is assigned to each $15 \mathrm{~s}$ measurement interval. Based on a histogram of all CBH within a 15 min block period at raw resolution of $10 \mathrm{~m}$, minimum $\mathrm{CBH}$ is taken as the first bin with at least two counts (i.e. $30 \mathrm{~s}$ ). Here, only $\mathrm{CBH} \leq 3000 \mathrm{~m} \mathrm{agl}$ are considered relevant for the ABL analysis. Cloud cover $(\mathrm{CC})$ at each $15 \mathrm{~s}$ interval is the percentage of times with $\mathrm{CBH} \leq 3000 \mathrm{~m}$ within the 30 -min moving window, this is block-averaged to $15 \mathrm{~min}$.

Table 2: Measurement locations and settings by sensor for the time periods analysed.

\begin{tabular}{llllll} 
Sensor & Site & $\begin{array}{l}\text { Scan } \\
\text { pattern }\end{array}$ & Time period analysed & $\begin{array}{l}\text { Vertical resolution [ m } \\
\text { ] }\end{array}$ & $\begin{array}{l}\text { Sensor height [m } \\
\text { agl] }\end{array}$ \\
\hline HALO-1 & KCL & SP $_{347}$ & $01 / 10 / 2010-22 / 11 / 2010$ & 30 & 33.9 \\
& KCL & SP $_{981}$ & $23 / 11 / 2010-18 / 02 / 2011$ & 30 & 33.9 \\
& WCC & SP $_{120}$ & $21 / 05 / 2011-11 / 01 / 2012$ & 30 & 15.0 \\
& IC & SP $_{3600}$ & $12 / 01 / 2012-08 / 02 / 2012$ & 30 & 34.0 \\
& WCC & SP $_{120}$ & $28 / 07 / 2012-17 / 08 / 2012$ & 30 & 15.0 \\
HALO-2 & NK & SP & $23 / 07 / 2012-17 / 08 / 2012$ & 18 & 0.0 \\
CL31-C & KCL & NA & $21 / 09 / 2010-02 / 03 / 2011$ & 10 & 32.9 \\
& MR & NA & $09 / 03 / 2011-31 / 12 / 2012$ & 10 & 4.5 \\
CL31-D & KCL & NA & $23 / 09 / 2010-07 / 01 / 2011$ & 10 & 32.9 \\
& RGS & NA & $19 / 01 / 2011-01 / 02 / 2011$ & 10 & 8.7 \\
& NK & NA & $02 / 02 / 2011-31 / 12 / 2012$ & 10 & 3.8
\end{tabular}

Results are analysed at their respective temporal resolution: $15 \mathrm{~min}$ (MLH), $30 \mathrm{~min}$ (MH at night) and $60 \mathrm{~min}$ (MH daytime). For the direct comparison of individual sampling intervals, MLH is block-averaged dynamically to match the temporal resolution of $\mathrm{MH}$. Common metrics are used to compare the various estimates: root mean square error (RMSE), mean bias error (MBE), mean absolute error (MAE), coefficient of determination $\left(\mathrm{R}^{2}\right)$, linear regression described by slope (a) and intercept (b), and hit rate (HR). The latter is defined as the percentage of discrepancies remaining below a set threshold. To account for different sources of uncertainty, individual thresholds are chosen when comparing supervised to automatic MLH results from the same ALC (1 m), supervised to automatic MLH results from two ALC (35 m), MH from two Doppler lidars (70 m), or MLH and MH (70 m).

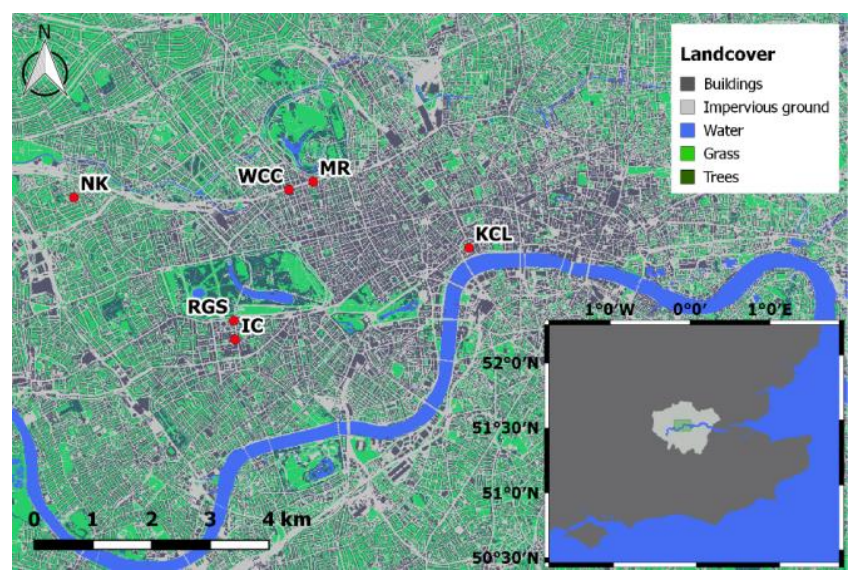

Figure 1: Measurement locations of Doppler lidars and ALC (Table 2) in central London, UK: North Kensington (NK), Royal Geographical Society (RGS), Imperial College (IC), Westminster City Council (WCC), Marylebone Road (MR), and King's College London (KCL). Inset shows location of central urban study areas within Greater London in Southeast England.

CABAM includes a module to detect occurrence of rainfall within the region analysed (here $<3 \mathrm{~km}$ ) based on the shape and magnitude of the attenuated backscatter profile. If complex rainfall patterns hinder the successful detection of MLH by CABAM, the 15 min period is flagged and excluded from analysis. Here, this flag is applied to the Doppler lidar MH 
estimates to ensure consistency. The high-resolution ALC rainfall flag was found more suitable than rainfall records from auxiliary surface observations (e.g. from a tipping bucket rain gauge).

\section{Results}

Various estimates of the turbulence-based MH and the aerosol-based MLH are compared using the supervised MLH estimates from ALC CL31-C as reference (Figure 2a-r, Table 3). The comparisons are shown for all available data (Figure 2a, g, m), for the inter-comparison period ('Int') when CL31-C and CL31-D (Figure 2b, h) or CL31-C and HALO-1 (Figure 2a), respectively, were operated at the same site (Table 2), and divided by season (Figure 2c-f; i-1; or). Days that fall in the respective Int period (CL31-D and CL31-C: 21/09/2010 - 07/01/2011; HALO-1 and CL31-C: 21/09/2010 - 02/03/2011) are excluded from the seasonal comparison which only shows observations gathered by sensors operating in differing locations. In addition, MH derived from Doppler lidar HALO-1 is compared to results based on observations of HALO-2 for a few weeks in summer 2012 (Figure 2s, Table 3).

These comparisons allow for sources of uncertainty in MLH detection to be explored (Sect. 3.1) that are associated with the MLH algorithm and ALC instrument-specific characteristics, respectively. To quantify the uncertainty in MH detection introduced by the choice of scan pattern (Sect. 2), an independent set of Doppler lidar observations is analysed (Sect. 3.2). The impact of operating two sensors of the same make and model at sites several kilometres apart (Figure 1) is assessed for both MLH and MH results (Sect. 3.3). Implications of sensor specifics and siting should be considered when comparing MH and MLH derived from turbulence- and aerosol-based retrievals, respectively (Sect. 3.4).

\subsection{Uncertainty in aerosol-derived mixed layer height}

It has been recognised that the major uncertainty in deriving MLH from attenuated backscatter is associated with the task of layer attribution (Haeffelin et al., 2012) as it can be challenging to determine which layer is associated with the top of the ML or the top of the residual layer (RL; Haman et al., 2012). The CABAM algorithm (Sect. 2) uses several decision criteria to track MLH through the day. Comparing CABAM MLH over London to temperature inversion heights determined from AMDAR profiles illustrates the ALC algorithm tends to assign MLH to a layer below the residual layer height during night and morning transition and the height of the ABL in the afternoon (Kotthaus and Grimmond, 2018a). This suggests, the task of layer attribution is generally accomplished successfully.

Kotthaus and Grimmond (2018a) report the greatest uncertainty of CABAM-derived MLH to be associated with the detection of layers in the near range $(<200 \mathrm{~m})$. Although near-range artefacts commonly found in Vaisala CL31 attenuated backscatter profiles (Kotthaus et al., 2016) are corrected on average, remains of these signatures and increased noise inherent in the lowest range gate can cause artificial vertical gradients at times (Kotthaus and Grimmond, 2018a). The CABAM algorithm includes a module to distinguish physically reasonable layers in the lowest few hundred metres from those introduced by artefacts and noise based on temporal height variability. This module could still be improved: the automatic procedure occasionally excludes a layer that appears to trace a real dynamic process, or the automatic procedure does not remove some artificial layers. A supervised operation of CABAM allows for these artefacts to be excluded and for the near-range module to be supported by manual layer selection (i.e. judge which layers should be considered for automatic MLH tracing). The supervised approach was performed for CL31-C operated at KCL and MR (Table 2).

In addition to the near-range artefacts, height-dependent averaging used in Vaisala firmware versions $<1.72$ (hardware generation 311) and < 2.03 (hardware generation 321) and the ripple effect associated with some transmitter components (Kotthaus et al., 2016) occasionally introduce artificial layers at higher ranges, especially when SNR is low. So far, no automatic procedure is available to exclude unwanted candidate layers $>200 \mathrm{~m}$ from CABAM MLH detection but they are addressed by the supervised CABAM procedure.

Within the period analysed (01/09/2010-31/12/2012), a MLH estimate is available for $86.9 \%$ and $87.1 \%$ of the time with attenuated backscatter profiles recorded with CL31-C when using the automatic (MLHCL31-C) and supervised (MLH_SCL31-C) detection, respectively. The value of MLH from CL31-C is altered by the supervised CABAM detection for only $1.28 \%$ of the available cases. For $0.1 \%$ a MLH estimate available via the automatic detection is removed during supervised detection. For $0.3 \%$ of the supervised results no detection is possible with the fully automatic procedure. As a consequence, few changes to the overall MLH results occur with most points falling on the 1:1 line (Figure 2a), consistent with a high correlation coefficient, negligible MBE and very high HR (Table 3).

While few changes occur during the inter-comparison period (Figure $2 b$ ), the remaining winter days (Figure 2c) and autumn (Figure 2f), the uncertainty associated with the automatic detection increases with absolute values of MLH. Hence, slightly more scatter and increased RMSE is found in spring (Figure 2d) and summer (Figure 2e), but the slope of the linear relations remains high and MAE and MBE low (Table 3). This demonstrates that general characteristics of MLH are captured well with the automatic procedure, although the supervised detection results may differ greatly for individual periods at times. The automatic detection underestimates MLH occasionally (spring and summer; Figure 2d, e), especially in the afternoon. In spring, the automatic detection tends to assign layers around $400 \mathrm{~m}$ as MLH (170 15 min-periods), when a higher layer appears to be more reasonable based on the supervised detection. These are likely associated with false layers introduced by the range-dependant internal averaging conducted in old firmware versions. In summer, most cases of MLH underestimation are associated with cloudy conditions (Figure S.1, Figure S.2) while 
overestimation very rarely occurs and is mainly associated with the evening transition around sunset, a time of great uncertainty in aerosol-based MLH detection. Aerosols dispersed within the ML likely form new layers after the turbulent mixing decays, gradients tend to be less pronounced and the presence of multiple layers makes the task of layer attribution challenging.

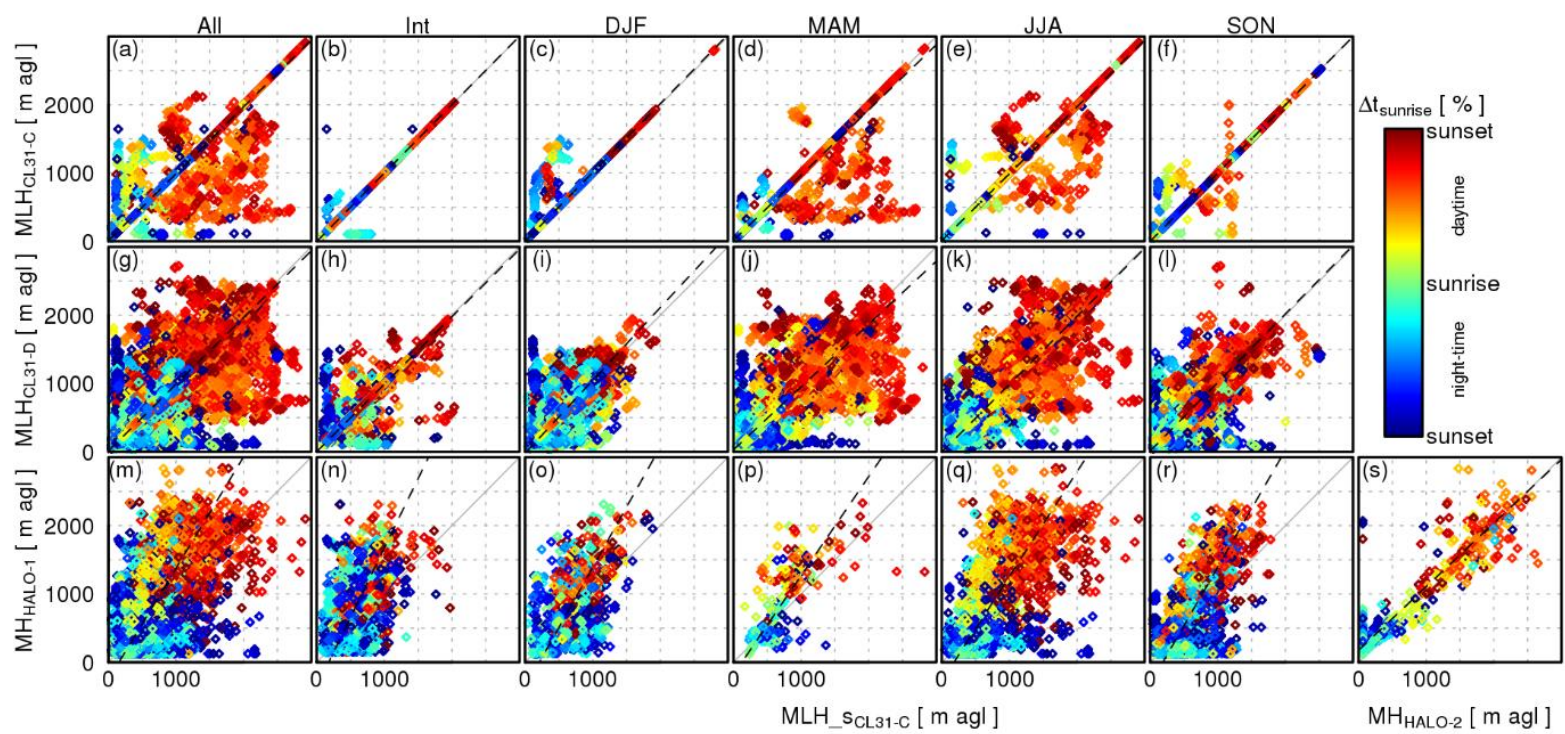

Figure 2: Aerosol-derived MLH from two ALC (CL31-C (a-f) and CL31-D (g-I)) and turbulence-derived MH from Doppler lidar HALO-1 (m-r) against (a-r) aerosol-derived MLH_s from CL31-C including supervised layer selection for $(a, g, m)$ all data available in 10/2010 $-12 / 2012$, (b, h, n) the inter-comparison period with the respective pair of sensors located at KCL (Table 2), and times with HALO-1, CL31-C and CL31-D at different locations (Table 2) separated by season: (c, i, o) winter, (d, j, p) spring, (e, k, q) summer, and (f, l, r) autumn; (s) shows comparison of MH from HALO-1 at WCC against HALO-2 at NK. Colours indicate time relative to sunrise. For the comparison of entirely automatic $\mathrm{MLH}_{\mathrm{CL} 31-\mathrm{C}}$ against supervised $\mathrm{MLH} \_\mathrm{S} \mathrm{CL31}-\mathrm{C}$, most points fall on the 1:1 line. Temporal resolution is $15 \mathrm{~min}$ for $\mathrm{MLH}, 1 \mathrm{~h}$ for $\mathrm{MH}$ during night, and $30 \mathrm{~min}$ for $\mathrm{MH}$ during day. For comparison between $\mathrm{MLH}$ and $\mathrm{MH}$ ( $\mathrm{m}-\mathrm{r}$ ), $\mathrm{MLH}$ is block averaged to match the resolution of $\mathrm{MH}$. (dashed line) linear relation with slope and intercept given in Table 3; (solid line) 1:1 line. This figure of all conditions can be compared to Figure S.1 for cloud-free and Figure S.2 for cloudy conditions.

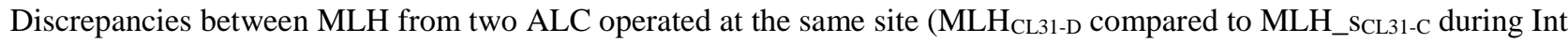
at KCL, Table 2) are larger (Figure 2h) than the uncertainties of CABAM (Figure 2b). While MBE is still small and the slope mostly close to unity (Table 3), the correlation between the two estimates is clearly reduced and more

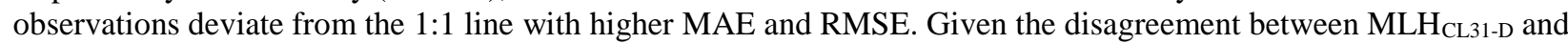
MLH_SCL31-C is often associated with layers in the lowest several hundred metres, an improved near-range module of CABAM could help to reduce the discrepancy in future studies. Especially during night when atmospheric mixing is reduced, it is challenging to automatically distinguish instrument related artefacts and actual atmospheric layers in the

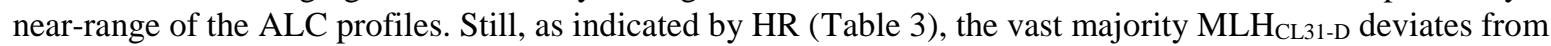
MLH_SCL31-C by less than $35 \mathrm{~m}$ (and $76 \%$ by less than $5 \mathrm{~m}$ ).

\subsection{Uncertainty in turbulence-derived mixing height}

The effect of using different scan patterns to measure the vertical velocity $(w)$, the variable used to determine $\mathrm{MH}$ (Sect. 2), is tested using data obtained with a non-scanning Halo Photonics Doppler lidar located at Chilbolton Observatory $\left(51^{\circ} 09^{\prime} \mathrm{N}, 01^{\circ} 26^{\prime} \mathrm{W}\right)$. It was run in vertical stare mode with a sampling frequency of $0.0256 \mathrm{~Hz}(1$ integration every $39 \mathrm{~s}$ ) and a range resolution of $36 \mathrm{~m}$. These observations are selected because the instrument was continuously operating in one scanning mode, so that any scan pattern can be simulated by using subsets of the measurements. Some gaps in the time series occur caused by, for example, low atmospheric aerosol concentrations. Cloud base height is defined simply as being the height at which Doppler lidar SNR increased above a threshold of $2 \mathrm{~dB}$ and ranged between $200 \mathrm{~m}$ and $1020 \mathrm{~m}$ agl. Nine days are selected for the scan pattern comparison: four with clear skies (28/09/2011-01/10/2011) and five cloudy days (17/06/2011, 28/06/2011, 07/09/2011, 21/11/2011, and 20/08/2012).

To simulate different scan patterns, the Chilbolton $w$ data at each height is linearly interpolated to a sampling frequency of $1 \mathrm{~Hz}$ (base case scenario) and then sampled every $4 \mathrm{~s}(0.25 \mathrm{~Hz})$ to approximate the London lidars' sampling rate. This time series is sub-sampled to mimic the vertical stare measurements of the four different scan patterns used in London (Sect. 2; Table 2). 


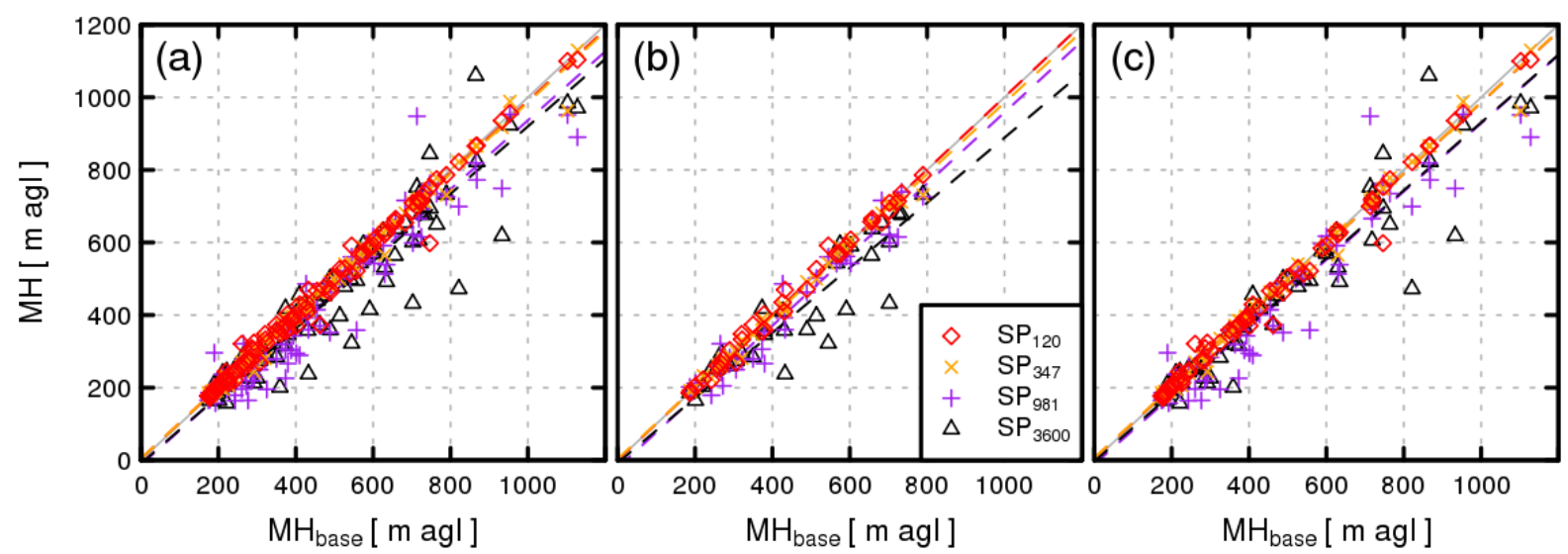

Figure 3: Mixing height $(\mathrm{MH})$ obtained for different scan patterns (Table 2) compared to the base case scenario scan pattern (continuous vertical stare at $1 \mathrm{~Hz}$ ) for (a) all days selected, (b) cloud-free days and (c) cloudy days. (dashed line) linear relation with slope and intercept given in

The scan patterns cause some differences from the base pattern (Figure 3, Error! Not a valid bookmark selfreference.). The $\mathrm{MH}$ observed with shorter cycle scan patterns ( $\mathrm{SP}_{120}$ and $\mathrm{SP}_{347}$ ) have generally very good agreement with the reference. Disagreement increases for longer cycle patterns $\left(\mathrm{SP}_{981}\right.$ and $\left.\mathrm{SP}_{3600}\right)$, likely because the smaller number of $w$ observations cause greater uncertainty in vertical velocity variance estimates. While comparison statistics are slightly better during clear-sky conditions (Table $4 \mathrm{~b}$ ) for $\mathrm{SP}_{120}, \mathrm{SP}_{347}$ and $\mathrm{SP}_{981}$, errors are slightly reduced during cloudy cases for $\mathrm{SP}_{3600}$ (Table 4c). Given the small sample size these results should be interpreted with care. Fortunately, the most erroneous scan pattern $\left(\mathrm{SP}_{3600}\right)$ was used for only 28 days in London (Table 2). Here we assume the uncertainty introduced from using a range of scan patterns is negligible. 
Table 4; (solid line) 1:1 line.

Table 3: Statistics of the comparison between MLH from CL31-C and CL31-D, and MH from HALO-1 against supervised MLH_s from CL31-C for all available data (Table 2), the inter-comparison period (Int) with sensors at the KCL site, and divided by season; last row of each: comparison of $\mathrm{MH}_{\text {HALO-1 }}$ against $\mathrm{MH}_{\text {HALO-2. }}$. Statistics ( $\mathrm{N}$ : number of samples, MAE: mean absolute error, MBE: mean bias error, RMSE: root mean square error, a: slope of linear correlation, $b$ : intercept of linear correlation, $\mathrm{R}^{2}$ : correlation coefficient, HR: hit rate with individual thresholds for $\mathrm{MLH}_{\mathrm{CL31-C}}(1 \mathrm{~m}), \mathrm{MLH}_{\mathrm{CL} 31-\mathrm{D}}(35 \mathrm{~m})$, and $\mathrm{MH}_{\text {HALO-1 }}(70 \mathrm{~m})$, respectively) correspond to scatterplots: a) all (Figure 2), b) cloud-free (Figure S.1), and c) cloudy (Figure S.2). Units are m (MBE, MAE, RMSE, b), dimensionless (N, a) and \% (HR).

\begin{tabular}{|c|c|c|c|c|c|c|c|c|c|c|c|c|c|c|c|c|c|c|c|c|c|c|c|c|c|}
\hline \multirow{2}{*}{ a) all } & & \multicolumn{8}{|c|}{ MLHCL31-C } & \multicolumn{8}{|c|}{ MLHCL31-D } & \multicolumn{8}{|c|}{ MHHALO-1 } \\
\hline & & $\mathrm{N}$ & MBE & MAE & RMSE & $\mathrm{a}$ & $\mathrm{b}$ & $\mathrm{R}^{2}$ & $\mathrm{HR}$ & $\mathrm{N}$ & MBE & MAE & RMSE & $\mathrm{a}$ & $\mathrm{b}$ & $\mathrm{R}^{2}$ & HR & $\mathrm{N}$ & $\mathrm{MBE}$ & MAE & RMSE & $\mathrm{a}$ & $\mathrm{b}$ & $\mathrm{R}^{2}$ & HR \\
\hline & All & 64416 & -3 & 10 & 95 & 0.98 & 9 & 0.95 & 99 & 55943 & -1 & 98 & 220 & 0.98 & 13 & 0.73 & 57 & 10020 & 102 & 263 & 3378 & 1.63 & -256 & 0.47 & 23 \\
\hline$\frac{1}{3}$ & Int & 8888 & 0 & 2 & 36 & 1.00 & -1 & 0.98 & 100 & 6649 & -3 & 42 & 158 & 0.99 & 3 & 0.72 & 89 & 3779 & 132 & 226 & 330 & 2.03 & -359 & 0.41 & 26 \\
\hline $\mathcal{H}_{0}$ & DJF & 13244 & 4 & 4 & 56 & 1.01 & 0 & 0.97 & 99 & 10845 & 13 & 90 & 193 & 1.07 & -22 & 0.61 & 56 & 1498 & 60 & 260 & 357 & 1.76 & -372 & 0.40 & 22 \\
\hline$I$ & MAM & 13947 & -15 & 20 & 149 & 0.95 & 15 & 0.90 & 97 & 12993 & -22 & 117 & 260 & 0.92 & 30 & 0.70 & 53 & 192 & 170 & 321 & 437 & 1.45 & -181 & 0.45 & 17 \\
\hline 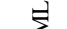 & JJA & 13728 & -5 & 15 & 115 & 0.98 & 12 & 0.95 & 98 & 12170 & -9 & 120 & 247 & 0.99 & -5 & 0.76 & 46 & 2301 & 111 & 337 & 478 & 1.53 & -276 & 0.49 & 19 \\
\hline & SON & 14609 & 0 & 4 & 50 & 1.00 & 1 & 0.98 & 99 & 13286 & 14 & 95 & 198 & 1.00 & 12 & 0.73 & 54 & 2250 & 65 & 247 & 343 & 1.71 & -320 & 0.48 & 22 \\
\hline $\mathrm{MH}_{\mathrm{HAl}}$ & & & & & & & & & & & & & & & & & & 427 & 118 & 215 & $5 \quad 326$ & 0.93 & 174 & 0.84 & 26 \\
\hline b) clea & & $\mathrm{N}$ & MBE & MAE & RMSE & $\mathrm{a}$ & $\mathrm{b}$ & $\mathrm{R}^{2}$ & $\mathrm{HR}$ & $\mathrm{N}$ & MBE & MAE & RMSE & $\mathrm{a}$ & $\mathrm{b}$ & $\mathrm{R}^{2}$ & HR & $\mathrm{N}$ & MBE & MAE & RMSE & $\mathrm{a}$ & $\mathrm{b}$ & $\mathrm{R}^{2}$ & $\mathrm{HR}$ \\
\hline & All & 16638 & 1 & 13 & 98 & 0.99 & 4 & 0.92 & 98 & 15067 & 8 & 102 & 208 & 1.05 & -17 & 0.66 & 53 & 2242 & -24 & 200 & 293 & 1.27 & -141 & 0.31 & 33 \\
\hline$\frac{1}{m}$ & Int & 1894 & -3 & C & 75 & 1.01 & -6 & 0.92 & 98 & 1319 & 17 & 66 & 183 & 1.07 & -12 & 0.61 & 82 & 680 & 45 & 166 & 248 & 1.58 & -157 & 0.24 & 40 \\
\hline $\mathcal{D}_{0}$ & DJF & 2532 & 9 & s & 72 & 1.01 & 5 & 0.94 & 98 & 2208 & 16 & 113 & 233 & 1.14 & -45 & 0.47 & 50 & 388 & -98 & 182 & 246 & 0.95 & -73 & 0.52 & 31 \\
\hline$I^{\prime}$ & MAM & 5080 & -8 & 15 & 107 & 0.95 & 17 & 0.91 & 97 & 4893 & -4 & 104 & 213 & 1.00 & -7 & 0.65 & 53 & 43 & 113 & 343 & 442 & 3.11 & -1195 & 0.13 & 12 \\
\hline 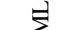 & JJA & 3044 & 12 & 24 & 150 & 1.03 & -2 & 0.86 & 97 & 2802 & 8 & 100 & 200 & 1.10 & -47 & 0.75 & 45 & 484 & -23 & 225 & 328 & 1.32 & -180 & 0.32 & 28 \\
\hline & SON & 4088 & 2 & 5 & 50 & 1.00 & 1 & 0.98 & 99 & 3845 & 17 & 105 & 201 & 1.05 & -3 & 0.66 & 49 & 647 & -61 & 219 & 321 & 1.35 & -219 & 0.28 & 32 \\
\hline $\mathrm{MH}_{\mathrm{HAl}}$ & & & & & & & & & & & & & & & & & & 103 & 119 & 187 & $7 \quad 246$ & 0.72 & 228 & 0.75 & 28 \\
\hline c) & & $\mathrm{N}$ & MBE & MAE & RMSE & $\mathrm{a}$ & $\mathrm{b}$ & $\mathrm{R}^{2}$ & $\mathrm{HR}$ & $\mathrm{N}$ & MBE & MAE & RMSE & $\mathrm{a}$ & $\mathrm{b}$ & $\mathrm{R}^{2}$ & $\mathrm{HR}$ & $\mathrm{N}$ & MBE & MAE & RMSE & $\mathrm{a}$ & $\mathrm{b}$ & $\mathrm{R}^{2}$ & $\mathrm{HR}$ \\
\hline & All & 47414 & -5 & $\mathrm{C}$ & $9 \quad 93$ & 0.98 & 10 & 0.95 & 99 & 40819 & -5 & 97 & 225 & 0.9 & 20 & 0.73 & 58 & 7778 & 138 & 281 & 1399 & 1.65 & -251 & 0.48 & 20 \\
\hline$\frac{1}{m}$ & Int & 6954 & 0 & c & 11 & 1 & 1 & 1 & 100 & 5329 & -8 & 37 & 15 & 0.9 & 2 & 0.7 & 91 & 3099 & 15 & 23 & 34 & 2.12 & -412 & & 23 \\
\hline J & DJF & 10628 & 4 & 4 & 51 & 1.01 & -2 & 0.97 & 99 & 8597 & 13 & 84 & 182 & 1.05 & -16 & 0.64 & 58 & 1110 & 115 & 287 & 388 & 1.9 & -414 & 0.38 & 19 \\
\hline$\Psi^{\prime}$ & MAM & 8784 & -20 & 24 & 168 & 0.96 & 13 & 0.89 & 97 & 8097 & -32 & 124 & 285 & 0.9 & 42 & 0.69 & 53 & 149 & 186 & 315 & 435 & 1.36 & -111 & 0.49 & 19 \\
\hline$\vec{E}$ & JJA & 10598 & -9 & 13 & 102 & 0.97 & 12 & 0.96 & 98 & 9358 & -14 & 126 & 260 & 0.98 & 1 & 0.74 & 46 & 1817 & 147 & 367 & 511 & 1.55 & -285 & 0.47 & 16 \\
\hline & SON & 10450 & -1 & 3 & 49 & 1 & 0 & 0.98 & 99 & 9438 & 13 & 90 & 196 & 0.99 & 17 & 0.74 & 56 & 1603 & 115 & 258 & 352 & 1.73 & -303 & 0.52 & 18 \\
\hline $\mathrm{MH}_{\mathrm{HAl}}$ & $\mathrm{LO}-2$ & & & & & & & & & & & & & & & & & 324 & 118 & 223 & 347 & 0.94 & 177 & 0.84 & 26 \\
\hline
\end{tabular}

The scan patterns cause some differences from the base pattern (Figure 3, Error! Not a valid bookmark self-

reference.). The $\mathrm{MH}$ observed with shorter cycle scan patterns $\left(\mathrm{SP}_{120}\right.$ and $\left.\mathrm{SP}_{347}\right)$ have generally very good agreement with the reference. Disagreement increases for longer cycle patterns $\left(\mathrm{SP}_{981}\right.$ and $\left.\mathrm{SP}_{3600}\right)$, likely because the smaller number of $w$ observations cause greater uncertainty in vertical velocity variance estimates. While comparison statistics are slightly better during clear-sky conditions (Error! Not a valid bookmark self-reference.b) for $\mathrm{SP}_{120}, \mathrm{SP}_{347}$ and $\mathrm{SP}_{981}$, errors are slightly reduced during cloudy cases for $\mathrm{SP}_{3600}$ (Error! Not a valid bookmark self-reference.c). Given the small sample size these results should be interpreted with care. Fortunately, the most erroneous scan pattern $\left(\mathrm{SP}_{3600}\right)$ was used for only 28 days in London (Table 2). Here we assume the uncertainty introduced from using a range of scan patterns is negligible. 
Table 4: Statistics of the comparison between MH from a HALO Doppler lidar operated at a rural site in continuous vertical stare mode using the various scan patterns (SP; Sect. 2) against the base case scenario (Sect. 3.2). Statistics (N: number of samples, MBE: mean bias error, MAE: mean absolute error, RMSE: root mean square error, a: slope of linear correlation, b: intercept of linear correlation, $\mathrm{R}^{2}$ : correlation coefficient) correspond to scatterplots in Figure 3: a) all, b) cloud-free, and c) cloudy. Units are $m$ (unless dimensionless)

\begin{tabular}{llllllll} 
a) all & $\mathrm{N}$ & $\mathrm{MBE}$ & $\mathrm{MAE}$ & $\mathrm{RMSE}$ & $\mathrm{a}$ & $\mathrm{b}$ & $\mathrm{R}^{2}$ \\
\hline $\mathrm{SP}_{120}$ & 100 & -2 & 12 & 23 & 0.98 & 5 & 0.99 \\
$\mathrm{SP}_{347}$ & 100 & -4 & 10 & 20 & 0.98 & 5 & 0.99 \\
$\mathrm{SP}_{981}$ & 97 & -36 & 50 & 73 & 0.95 & -13 & 0.92 \\
$\mathrm{SP}$ & 92 & -42 & 56 & 88 & 0.93 & -8 & 0.88 \\
$\mathrm{~b})$ clear & $\mathrm{N}$ & $\mathrm{MBE}$ & $\mathrm{MAE}$ & $\mathrm{RMSE}$ & $\mathrm{a}$ & $\mathrm{b}$ & $\mathrm{R}^{2}$ \\
\hline $\mathrm{SP}_{120}$ & 35 & 1 & 13 & 18 & 1.00 & 1 & 0.99 \\
$\mathrm{SP}_{347}$ & 35 & -5 & 9 & 15 & 0.98 & 4 & 0.99 \\
$\mathrm{SP}_{981}$ & 33 & -30 & 43 & 53 & 0.98 & -21 & 0.94 \\
$\mathrm{SP}_{3600}$ & 33 & -55 & 61 & 90 & 0.90 & -7 & 0.85 \\
$\mathrm{c}$ cloudy & $\mathrm{N}$ & $\mathrm{MBE}$ & $\mathrm{MAE}$ & $\mathrm{RMSE}$ & $\mathrm{a}$ & $\mathrm{b}$ & $\mathrm{R}^{2}$ \\
\hline $\mathrm{SP}_{120}$ & 65 & -4 & 12 & 25 & 0.98 & 5 & 0.99 \\
$\mathrm{SP}_{347}$ & 65 & -3 & 10 & 22 & 0.98 & 6 & 0.99 \\
$\mathrm{SP}_{981}$ & 64 & -39 & 54 & 81 & 0.94 & -11 & 0.92 \\
$\mathrm{SP}_{3600}$ & 59 & -35 & 53 & 87 & 0.93 & -4 & 0.89
\end{tabular}

\subsection{Detecting mixing height (MH) and mixed layer height (MLH) at nearby sites}

The MH from HALO-1 and HALO-2 operated with scan pattern $\mathrm{SP}_{120}$ at two sites within central London (WCC and NK, Table 2) have good agreement with a high correlation coefficient (Table 3). However, overall statistics indicate MH from HALO-1 at WCC is higher than from HALO-2 at NK $(\mathrm{MBE}=118 \mathrm{~m}, \mathrm{MAE}=215 \mathrm{~m})$. This bias is mostly associated with nocturnal conditions when $\mathrm{MH}_{\mathrm{HALO}-2}<500 \mathrm{~m}$ agl, leading to an intercept of the linear relation of $174 \mathrm{~m}$ and a slope below unity (Table 3). While $\mathrm{MH}_{\mathrm{HALO}-2}$ is lower than $\mathrm{MH}_{\mathrm{HALO}-1}$ during most nights, the HALO-2 results very frequently suggest $\mathrm{MH}$ to be below the vertical detection limit of $63 \mathrm{~m}$ at this site (MH is set to this value in such cases) while HALO-1 mostly detects a layer $>200 \mathrm{~m}$. This may be caused by differences in nocturnal sensible heat fluxes (reducing vertical mixing) but the lack of flux observations and being close to the detection limits at both sites means this difference cannot be explained here. ALC observations at NK (CL31-D) and (MR, i.e. near WCC) suggest atmospheric stratification does not seem to favour a fast settling of the aerosols during these nights. Both MLH results generally agree with the nocturnal MH values at WCC (not shown). For the period with both Doppler lidars operational $(28 / 07 / 2012-17 / 08 / 2012)$ MLH from the ALC at MR and NK is in slightly better agreement $(\mathrm{MBE}=-37 \mathrm{~m}$; MAE $=$ $138 \mathrm{~m} ; \mathrm{RMSE}=269 \mathrm{~m}$ ) than $\mathrm{MH}$ from two sensors at different sites with similar distance. Given the importance of the NK and MR air quality monitoring stations (e.g. Harrison, 2017), future studies should instrument and continue to investigate the relation of turbulent mixing and vertical aerosol dispersion in this area.

Discrepancies between MLH estimates derived from the two ALC located at MR and RGS or NK (distance between MR and RGS or NK $\approx 3-4 \mathrm{~km}$ ), respectively (Table 2), are slightly increased (Table 3; Figure 2i-1) compared to results determined for the same two sensors operated in close vicinity during the inter-comparison setup (Int, Sect. 3.1), i.e. the reduction in HR reveals the spatial displacement has a systematic effect. Temporal analysis (not shown) does not identify a specific time of day associated with the increased discrepancies. Detailed case studies may reveal certain conditions when MLH characteristics vary spatially even within the central London study area (e.g. spatial variations associated with sea breeze fronts have been illustrated based on the ALC measurements; Bohnenstengel et al., 2015b), however, analysis of such special cases is beyond the scope of this study. As both positive and negative MLH differences occur, the MBE remain very small and the linear relations are described by a slope close to unity and minimal intercept. The increase in RMSE and MAE for MLH during spring and summer is also found in the comparison between the automatic and supervised detection from the same sensor (MLHCL31-C Vs. MLH_SCL31-C). This suggests, general features of MLH at the central London sites (Figure 1) are very similar or subtle differences are often undetectable due to algorithm- and sensor-related uncertainties (Sect. 3.1). Hence, it is considered acceptable to combine observations across sites when calculating overall diurnal trends (Sect. 3.4.4).

\subsection{Comparison of mixing height and mixed layer height}

The turbulence-derived MH from Doppler lidar HALO-1 and supervised, aerosol-derived MLH from ALC CL31-C are compared for all days with data available from both sensors: irrespective of measurement site (Figure $2 \mathrm{~m}$ ), for the intercomparison period (Table 2) with the two sensors operating at KCL (Figure 2n), and for the remaining time separated by season (Figure 2o-r).

Overall (Table 3), MHHALO-1 tends to exceed MLH_SCL31-C $(\mathrm{MBE}=102 \mathrm{~m}$; MAE $=263 \mathrm{~m})$. However, for MH $<1000 \mathrm{~m}$ agl, MLH is often higher than the turbulence-derived MH so the linear regression intercept is strongly negative and the slope around 1.5-2.0. Again, MBE and RMSE increase with general magnitude of MH and MLH so that nominal discrepancy between the estimates is greatest in spring and summer. 
The most distinct difference between MH and MLH occurs during the morning when the boundary layer is growing.

This is particularly evident during summer (Figure 2q) when MH can be more than twice MLH around $4 \mathrm{~h}$ after sunrise. From about $8 \mathrm{~h}$ after sunrise, the MH and MLH estimates converge again. Occasionally in summer MLH is about twice $\mathrm{MH}$ just before sunset (i.e. 16-18 h after sunrise). These situations are usually associated with clouds (cf. Figure S.1q and Figure S.2q). During cloud-free conditions, MLH frequently exceeds MH so the overall bias is negative and the slope is below unity during winter.

Over- and underestimations of MLH compared to MH occur both during cloudy and ABL cloud-free situations (Figure S.1, Figure S.2, Table 3b,c). To investigate the conditions that determine agreement between the two layers, case studies are analysed when the ALC and Doppler lidar are in close vicinity (either both at KCL or HALO-1 at WCC and CL31 at MR, Figure 1) to eliminate spatial effects.

\subsubsection{Role of vertical mixing and atmospheric stability}

The case studies of fully or partly cloud-free ABL conditions reveal a significant impact of the vertical mixing on the diurnal patterns of $\mathrm{MH}$ and MLH and their relative agreement (Figure 4). In response to strong turbulent mixing (Figure 4a), clear diurnal dilution variations are evident from the attenuated backscatter profiles (Figure 4b) and MLH rises in the morning with a delay of about $1.5 \mathrm{~h}$ relative to $\mathrm{MH}$. On most days, afternoon values of $\mathrm{MH}$ are $100-350 \mathrm{~m}$ greater than MLH, but still mark the top of the same layer.

On 30/09/2011 MLH picks up an aerosol layer $680 \mathrm{~m}$ below MH. Analysis of numerical weather prediction model fields (Lean et al., in preparation) reveals a weak temperature inversion is present at around $760 \mathrm{~m}$ agl on this day, below the capping inversion, suggesting that the aerosol-derived MLH is actually associated with a layer with increased static stability. If the mixing layer is composed of two sub-layers such as in this case, uncertainty in layer attribution is significant for both MH and MLH detection techniques. While MH and MLH often decay nearly simultaneously in the afternoon, a clear delay is found in the evening of the 02/10/2011 as vertical gradients in attenuated backscatter are less pronounced than on the preceding days (Figure 4b). The MLH follows the top of the aerosol layer at the height of the daytime MLH well into the night. MH and MLH show very good agreement during stable nocturnal stratification (Figure 4a,b). If aerosols and moisture are well-dispersed within the ABL and stratification is rather unstable (Figure 4c-f), large differences may occur with either bias possible. For partly cloudy conditions with strongly unstable atmospheric stratification presumably extending above the ABL as indicated by clouds and light rainfall (13/12/2011; Figure 4e), temporal variability in MH is clearly increased and MH exceeds MLH by several hundred metres even before sunrise.
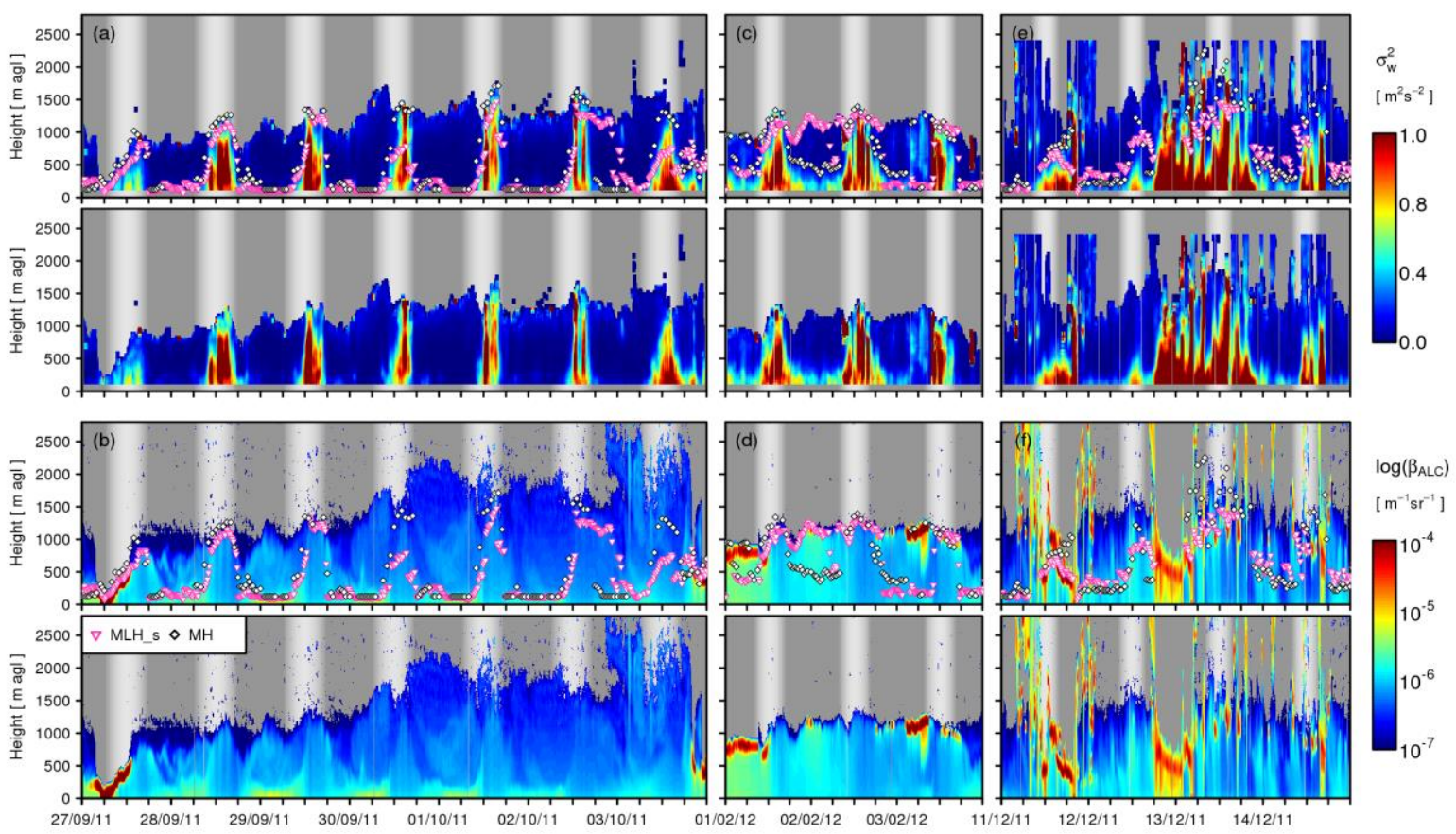

Figure 4: (a, c, e) Vertical velocity variance and $(b, d, f)$ logarithm of attenuated backscatter with respective top panels showing MLH_s and $\mathrm{MH}$ estimates as symbols for case study periods with $(\mathrm{a}, \mathrm{b})$ mostly cloud-free conditions with clear signature in diurnal dilution, (c, d) partly cloudy conditions with vertically distributed aerosol and moisture, and (e, f) partly cloudy conditions with strong vertical motion and some precipitation. Background shading represents solar zenith angle. Precipitation and clouds cause high values of attenuated backscatter $\left(>10^{-5}\right)$. 


\subsubsection{The role of convective clouds}

The presence of clouds can affect retrievals of both MH and MLH and hence their relative agreement (Figure 5). On days with ABL clouds following a night without clouds or nocturnal MLH < CBH, morning growth rates of MLH are often very high (Kotthaus and Grimmond, 2018b; Pal and Haeffelin, 2015), as seen in the selected ABL cloud case study days (Figure 5a-d). Nocturnal values of MH and MLH generally capture the same layer on most nights. The MH may be both slightly higher (30/06/2011-01/07/2011; 03/07/2011-04/07/2011; 10/08/2012-11/08/2012) or lower (02/07/2011-03/07/2011; 09/08/2012-10/08/2012) than MLH by up to about $200 \mathrm{~m}$. During daytime continuous, onelayer Cumulus clouds at the top of the ABL, MH and MLH are very similar (Figure 5a-d).

Discrepancy increases with cloud complexity, e.g. when two cloud layers are present (02/07/2011, Figure 5a,b) or broken fair-weather Cumuli appear (e.g. 09/08/2012, Figure 5c, d). In the latter case, turbulent vertical motion might not be well-established up to cloud level. For very complex convective clouds (causing scattered regions of high $\beta$ in Figure 5e-h), MH can be 2-3 times the MLH (CABAM does not allow MLH to be located far above CBH) and temporal variability in $\mathrm{MH}$ is generally high with fluctuations of hundreds of metres between individual 60 min periods.

MLH is restricted by the vertical dilution of aerosols and moisture within the ABL. Where particle concentrations are generally low, the SNR below cloud level might not be sufficient to determine a clear ALC signal (e.g. Figure 5f) introducing increased uncertainty to the MLH detection compared to cases with more ABL particles present (e.g. Figure $5 b, d)$. Rainfall can introduce complex layering within the ABL that makes the task of layer attribution more challenging (Figure 5h). Despite the vertical variability in attenuated backscatter during this latter case, the aerosol layers traced by MLH appear to be associated with changes in the vertical velocity variance (Figure $5 \mathrm{~g}$ ) in a similar manner as on more simple days (Figure 5a, c).
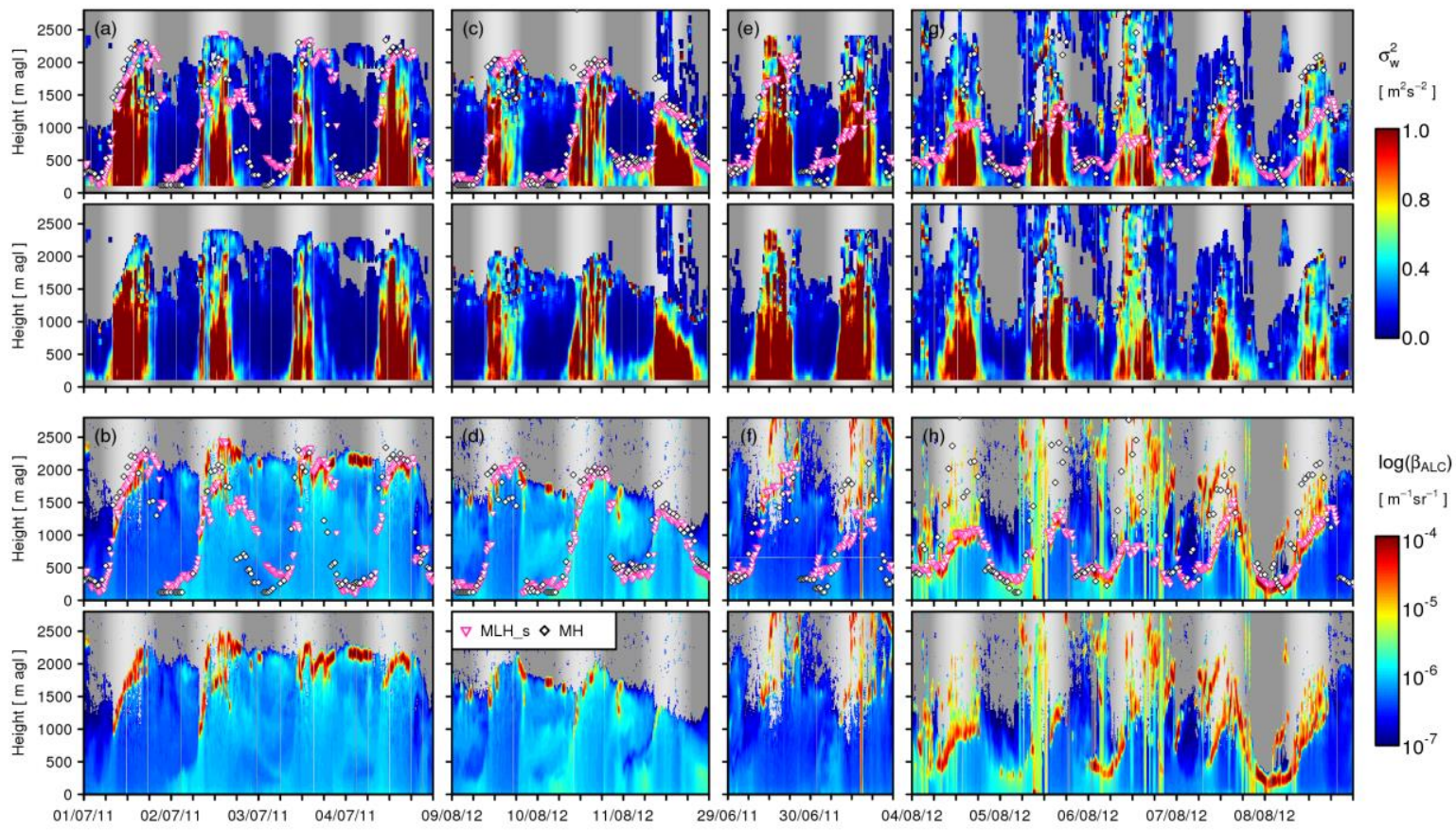

Figure 5: (a, c, e, g) Vertical velocity variance and $(b, d, f, h)$ logarithm of attenuated backscatter with respective top panels showing MLH_s and MH estimates as symbols for case study periods with $(a, b, c, d)$ boundary layer clouds forming at the top of the ABL, (e, f) convective clouds forming on top or above the $A B L$, and $(g, h)$ convective clouds on top or above the $A B L$ with precipitation. Background shading represents solar zenith angle. Precipitation and clouds cause high values of attenuated backscatter $\left(>10^{-5}\right)$.

\subsubsection{The role of stratiform clouds}

MLH and MH have very good agreement when stratiform ABL cloud is present (Figure 6). However, the relation between cloud- and surface-driven turbulence is of great importance for both retrievals. If the cloud is mostly decoupled from the mixing layer below (e.g. Figure 6a,b) MLH is often marked by a clear gradient in attenuated backscatter. MH generally agrees very well with this layer estimate as weak unstable conditions persist during both night and day. For the cases presented here, values of MH are on average about $130 \mathrm{~m}$ higher than MLH when both coincide with the cloud layer. If the cloud-driven turbulence is relatively strong compared to the signal in the mixing layer (e.g. 02/01/2011), MH suggests there is a continuous layer of turbulence extending up to the cloud. Changes between these two states can introduce very high temporal variability of $\mathrm{MH}$ and derived growth rates might not represent actual surface-driven mixing processes. The simple threshold algorithm (Sect. 2) for MH does not distinguish between cloudand surface-driven turbulence, but additional constraints, such as turbulence skewness can be used to distinguish downward-driven mixing due to cloud-top cooling, from upward-driven convection (Hogan et al., 2009). 
If surface-driven turbulence reaches up to the cloud layer during daytime (Figure 6c) both MLH and MH exhibit a transition between a below-cloud layer and the cloud layer during daytime. For stratiform clouds closer to the ground, significant vertical gradients in attenuated backscatter below the cloud are rare (Figure 6f), presumably because surfaceand cloud-driven turbulence might merge even during night time (Figure 6e). Both MH and MLH are mostly located near $\mathrm{CBH}$ (with $\mathrm{MH}>\mathrm{MLH}$ ). $\mathrm{MH}$ may be detected below $\mathrm{CBH}$ when surface-driven turbulence might be decoupled from the cloud layer (e.g. during the night 28/01/2011-29/01/2011). If this detachment between surface and cloud lasts sufficiently long for aerosols to settle a new layer boundary may form and the MLH coincides with this lower nocturnal layer, otherwise, the aerosol-derived MLH does identify a layer forming below the cloud.

Both the Doppler lidar and ALC signals are strongly attenuated within thick water clouds so no observations are available far above the cloud base and MH and MLH are practically restricted by their respective SNR filter. The physical interpretation of these layer estimates within stratiform clouds needs to be investigated in future studies that consider cloud physics and dynamics.
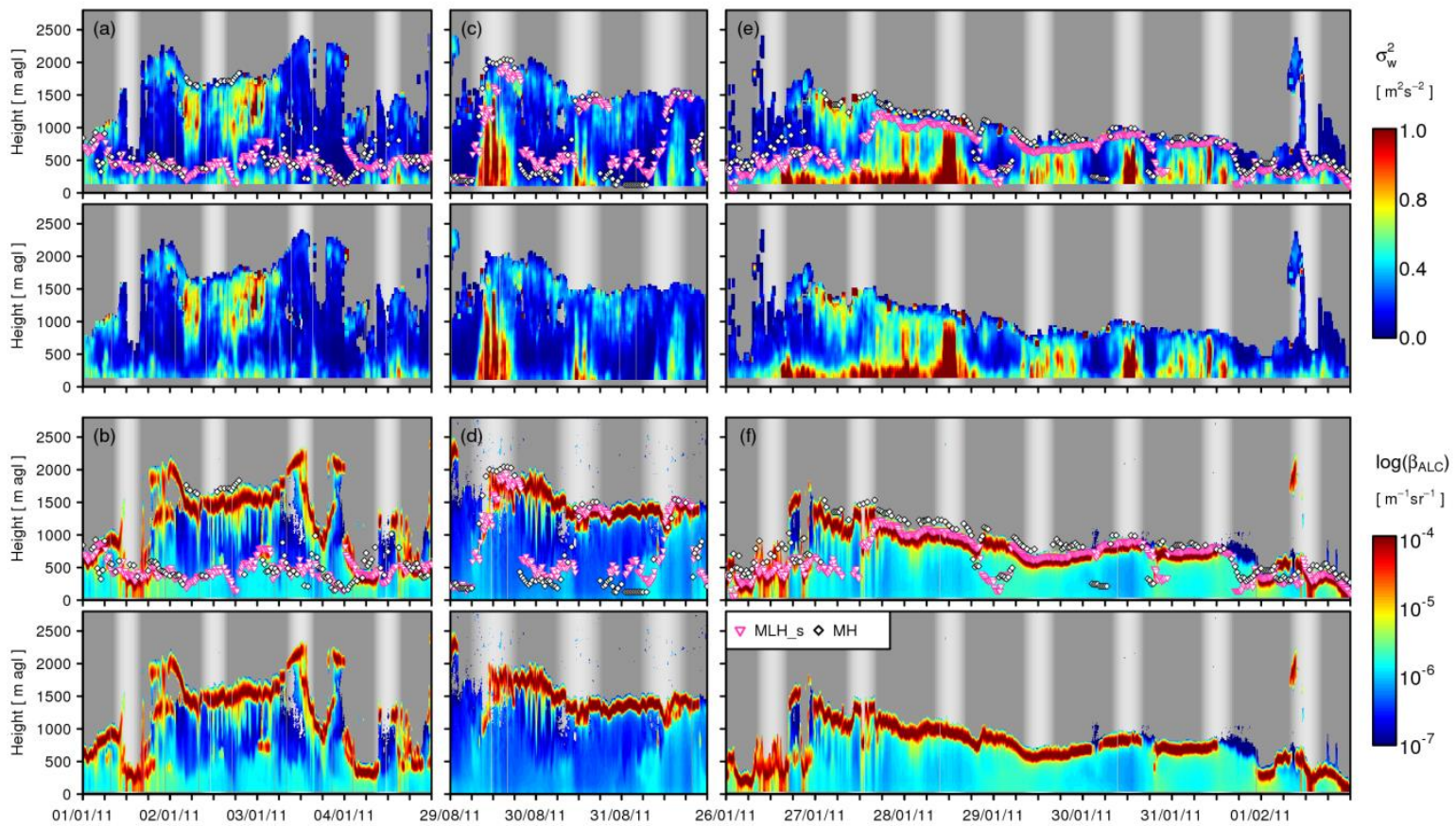

Figure 6: $(a, c, e)$ Vertical velocity variance and $(b, d, f)$ logarithm of attenuated backscatter with respective top panels showing MLH_s and $\mathrm{MH}$ estimates as symbols, for case study periods with stratiform clouds at the top of the ABL. Background shading represents solar zenith angle. Precipitation and clouds cause high values of attenuated backscatter $\left(>10^{-5}\right)$.

\subsubsection{Average diurnal characteristics}

Given the impact of cloud cover and cloud type on the diurnal evolution of the ABL (Kotthaus and Grimmond, 2018b) and the relation between turbulence-derived MH and aerosol-derived MLH (Sect. 3.4.1-3.4.3), the median diurnal pattern of the two layer estimates is calculated both by season and ABL class (Figure 7). Classification is taken from the CABAM results (Kotthaus and Grimmond, 2018a). Median diurnal patterns of cloud base height in London can be found in the supplementary material of Kotthaus and Grimmond (2018b).

As expected, solar geometry (i.e. time of day and day in year) clearly affects both MLH (Kotthaus and Grimmond, $2018 \mathrm{~b}$ ) and $\mathrm{MH}$. Various indicators are used in the literature to define the morning growth phase (including sunrise, sensible heat flux cross-over, and thresholds for layer increments e.g. Halios and Barlow, 2017). Here, the Kotthaus and Grimmond (2018b) approach is chosen: morning growth phase starts (ends) at the first (last) time when the layer exceeds (remains below) a value of its nocturnal minimum plus $10 \%(80 \%)$ of the diurnal range before reaching its daily maximum. Accordingly, the evening decay phase is considered to start (end) when the layer is lower (higher) than the daily maximum minus $20 \%(80 \%)$ of the diurnal range for the first (last) time after its peak (the beginning of the evening decay phase). To account for solar geometry, morning growth period start and end are normalised by daylength and evening decay period start and end are normalised by night-length (as suggested by Kotthaus and Grimmond, 2018b) for comparison of overall daily statistics.

While nocturnal values of MH and MLH have both good agreement or bias in either direction (Sect. 3.4.1-3.4.3), averages agree for most seasons and classes within their respective uncertainty (IQR shading, Figure 7). Both layer estimates generally have higher values during cloudy nights than under clear-sky conditions (Barlow et al., 2011; Kotthaus and Grimmond, 2018b). While some MLH might have the tendency to be slightly higher than MH during clear nights in summer (Figure 7e,h) and autumn (Figure 7i) and MH at times exceeds MLH on average under cloud- 
free conditions in winter (Figure 7d), the overall median MLH for clear nights (158 $\mathrm{m}$ ) is practically the same as that of MH (153 m). For cloudy nights, the median minima are very similar $(\mathrm{MH}=270 \mathrm{~m}, \mathrm{MLH}=258 \mathrm{~m})$. These tendencies agree with Barlow et al.'s (2011) autumn results that found MH to be slightly shallower than MLH during cloud-free nights on average.

Attenuated backscatter not only increases due to the presence of aerosol but also through their hygroscopic growth (Haeffelin et al., 2016). Cooling or warming of certain layers can result in gradients of attenuated backscatter through the increase or decrease in relative humidity (Gibert et al., 2007), including a hysteresis effect as aerosol scattering properties differ for the two cases (Randriamiarisoa et al., 2006). Hence, it can be expected that some nocturnal discrepancies between MH and MLH occur when humidity profiles are not altered through turbulent mixing processes but rather radiative cooling. In such cases, the turbulence signature traced by MH might not coincide with the mixed layer defined as the volume comprising well-dispersed aerosol and humidity: indeed, a "well-mixed layer" is not expected during stable conditions.

Especially in summer, the diurnal patterns (Figure 7a, e, h, k) clearly illustrate that $\mathrm{MH}$ starts growing earlier in the morning compared to MLH. On average, the morning growth of MH starts after about 5-10\% of the day-length and MLH after about 16-19\%. For cloudy winter days, MLH often rises simultaneously or even ahead of MH. However, these findings should be interpreted with care as layer attribution is challenged in the presence of shallow clouds for both MLH and MH retrieval algorithms. A longer analysis period would be required to permit more robust conclusions. The median delay in rise of MLH relative to MH is maximal (1 h $45 \mathrm{~min}$ ) for convective cloud conditions in summer. This is similar to Barlow et al.'s (2011) MH increase of 1-2 $\mathrm{h}$ ahead of the MLH derived from Doppler lidar backscatter (19 days, autumn) averaged across clear and cloudy conditions. During morning growth there may be strong gradients in particle concentration, particle type and humidity between the mixed layer and residual layers above, so that entrainment of drier air can delay the apparent rise of MLH. Whilst hygroscopic aerosol growth has been frequently cited as playing a role for MLH detection (Barlow et al., 2011; Pearson et al., 2010; Schween et al., 2014), detailed profile information on both humidity and aerosol composition would be required to quantify such physico-chemical mechanisms.

Not only does the MH start to grow earlier, it also often rises more rapidly. MH grows $\sim 1.5(\sim 2.0)$ times as fast as MLH for convective clouds (Figure $7 \mathrm{j}, \mathrm{k}, 1$ ) and stratiform clouds (Figure $7 \mathrm{~m}, \mathrm{n}$ ), respectively. Only for cloud-free days in winter and summer, the median growth rate of MLH $\left(202 \mathrm{~m} \mathrm{~h}^{-1} ; 190 \mathrm{~m} \mathrm{~h}^{-1}\right)$ is slightly higher than or similar to that of $\mathrm{MH}\left(181 \mathrm{~m} \mathrm{~h}^{-1} ; 198 \mathrm{~m} \mathrm{~h}^{-1}\right.$ ). While median growth rates of MLH distinctly differ between classes (from $89 \mathrm{~m} \mathrm{~h}^{-1}$ for stratiform clouds to $245 \mathrm{~m} \mathrm{~h}^{-1}$ for clear nights followed by convective cloud days), the range in growth rates of $\mathrm{MH}$ is smaller (178-284 $\left.\mathrm{m} \mathrm{h}^{-1}\right)$. For MLH, growth rates during clear-sky days and convective cloud days are close to the overall average, while for $\mathrm{MH}$ growth rates for the convective class $\left(283 \mathrm{~m} \mathrm{~h}^{-1}\right)$ are similar to cloudy days following cloud-free nights. The morning growth period lasts about $38 \%$ of the day-length for both MH and MLH, so the latter stagnates later (at $\approx 57 \%$ of the day) than the turbulent mixing height $(\approx 44 \%$ of the day). Both layer estimates have the longest morning growth period during clear-sky conditions. Accordingly, maximum MLH is reached between $71 \%$ (convective clouds) and 80\% (cloud-free) of the day, while MH peaks between 58-69\% of the day-length, respectively, so that $\mathrm{MH}$ reaches its maximum about 20 min (convective cloud days in winter) - $1 \mathrm{~h} 45$ min (convective cloud days in summer) ahead of MLH. 


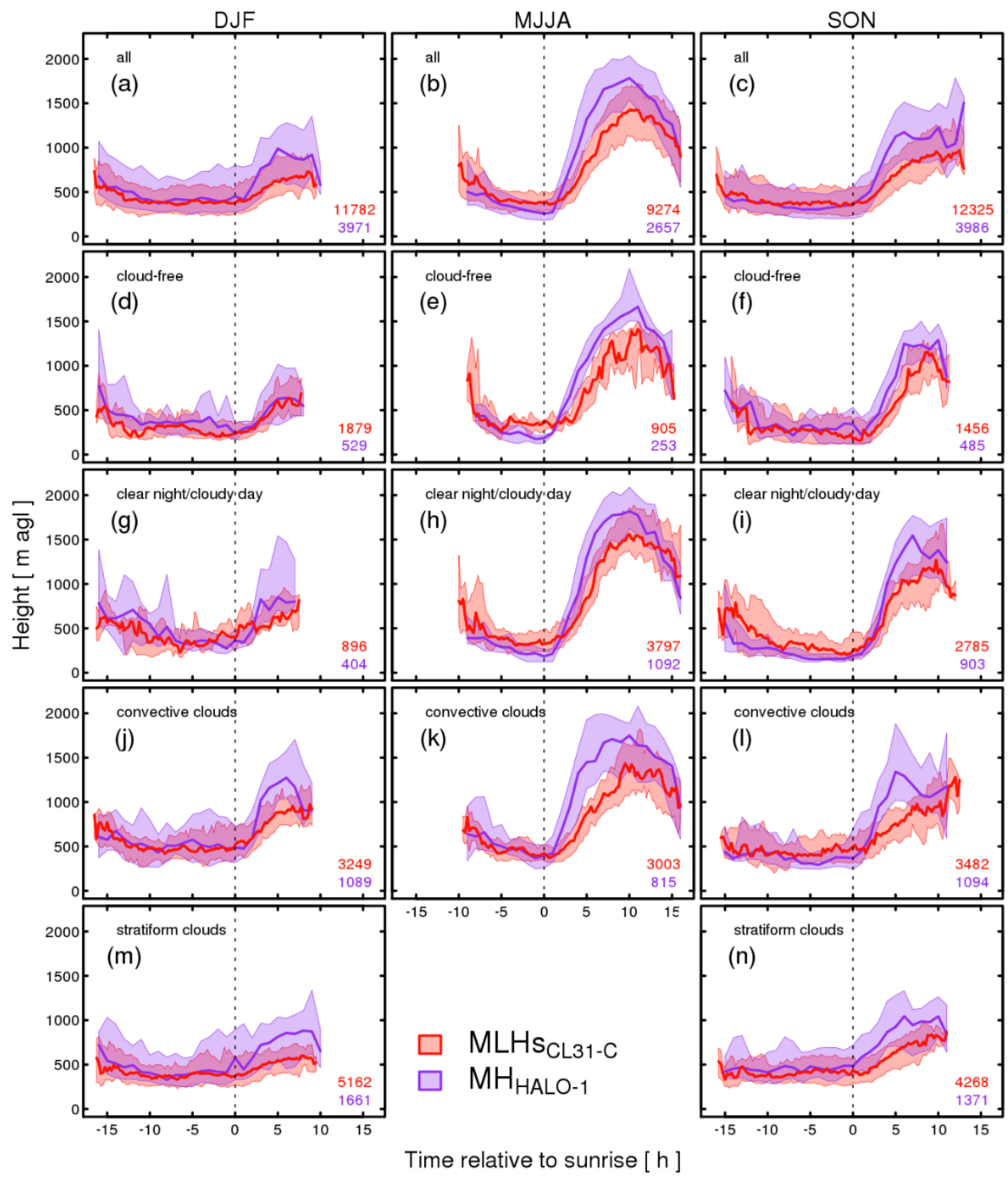

Figure 7: Median diurnal pattern with inter-quartile range (shading) of turbulence-derived $\mathrm{MH}$ ( $1 \mathrm{~h}$ and 30 min resolution during night and day, respectively) from Doppler lidar and aerosol-derived MLH (15 min) from ALC against time relative to sunrise for (a-c) all days with both HALO-1 and CL31-C data available and separated into (d-f) cloud-free conditions, (g-i) clear nights followed by cloudy days, $(j-1)$ convective cloud conditions, and $(m, n)$ stratiform cloud conditions. Columns separate days by season: $(a, d, g$, j, $m)$ winter, (b, e, h, k) May and summer, and (c, f, l, l, n) autumn, respectively. ABL classification according to CABAM results (Sect. 2). Number of available data points are listed in each subplot. Figure S3 presents this centred on sunset.

For both layer estimates, the daytime maxima increase with day-length and values are highest for convective cloud days following clear-sky nights $(\mathrm{MH} \approx 1795 \mathrm{~m}$ agl; $\mathrm{MLH} \approx 1409 \mathrm{~m}$ agl) and lowest for stratiform clouds $(\mathrm{MH} \approx 1055 \mathrm{~m}$ agl; $\mathrm{MLH} \approx 747 \mathrm{~m} \mathrm{agl}$ ). Daily maximum MH is greater than that of MLH in most conditions apart from winter clear-sky days (Figure 7d). Maxima are generally more similar in the absence of clouds (median difference of maxima $\approx 100 \mathrm{~m}$ ) and the discrepancy is most striking (Figure 7k) for convective cloud conditions (median difference of maxima $\approx$ $273 \mathrm{~m}$ ). This is likely related to the complex cloud patterns (Figure $5 \mathrm{~g}, \mathrm{~h}$ ) that fall within this category. But the structural offset between MLH and MH found for stratiform clouds (Figure 6) is confirmed by the diurnal cycles during daytime (Figure 7m,n).

Barlow et al. (2011) also found daytime maxima of MH and MLH to agree best during clear-sky days and MH to considerably exceed MLH during cloudy cases. Given they do not distinguish between convective and stratiform cloud conditions, it is likely that a dominance of the latter during their autumn study period explains the fact that both layer estimates are smaller for cloudy compared to clear-sky daytime conditions. Schween et al. (2014) report daytime MLH to generally exceed $\mathrm{MH}$, especially during morning and afternoon, indicating the MLH often falsely follows the top of the residual layer rather than the actual mixed layer height. Given their study uses the STRAT-2D algorithm (Haeffelin et al., 2012; Morille et al., 2007) which was developed based on high SNR observations of an aerosol lidar, with an old ALC model that is more prone to noise and instrument related artefacts (Kotthaus et al., 2016), false layer attribution is likely to occur frequently. In contrast, the MLH analysed here is derived after careful quality control using an algorithm specifically accounting for instrument specifics of low-power ALC (Kotthaus and Grimmond, 2018a). Furthermore, 
hygroscopic growth effects causing differences between MH and MLH are likely to be quite different in the cooler and more humid rural setting of the Schween et al. (2014) study compared to the drier, more polluted, central urban environment of this study. Another potential factor that might affect the agreement between MLH and MH is the choice in vertical threshold used to assign MH. Applying a slightly higher threshold (e.g. Schween et al., 2014 use $0.16 \mathrm{~m}^{2} \mathrm{~s}^{-2}$ ) might decrease daytime MH values drawing them closer to MLH.

The onset of the MH evening decay phase is found earlier (14-29\% of the night-length before sunset for clear-sky and convective cloud conditions, respectively) compared to MLH (6-12\%) and it also ends slightly earlier (8\% of nightlength after sunset for MH and 13\% for MLH). However, as MLH decays more rapidly on average by about $40 \mathrm{~m} \mathrm{~h}^{-1}$, the turbulence-derived mixing height and the aerosol-derived mixed layer height converge at around or shortly after sunset (Figure S.3). This conclusion contradicts some other studies that find the whole decay period of MLH to be clearly delayed relative to MH (especially for clear-sky conditions, e.g. Barlow et al., 2011) or attest MLH stagnates or slightly continues to increase up to sunset (e.g. Schween et al., 2014). As the case studies show (Sect. 3.4.1, Figure 4a,b), MLH in this study occasionally follows an elevated layer above MH even after sunset before converging to the same layer. It is possible that such conditions are more frequent in the short case study period analysed by Barlow et al. (2011).

The evening transition is a difficult time period for the accurate assignment of MLH based on aerosol profiles. Given new gradients in attenuated backscatter form slowly in response to decaying turbulence, contrast between layers is usually weak and algorithms solely based on absolute thresholds or idealised profiles might often not be sensitive to these subtle vertical variations. Another important factor for MLH detection in this transition phase is the ability of the lidar to observe shallow layers. If high-quality profile observations are available only above a certain height above ground due to the instrument's blind zone or uncertainty from incomplete optical overlap, a new nocturnal layer forming near the ground at or after sunset might not be detectable. In such cases, MLH algorithms tend to choose an elevated layer such as the top of the residual layer instead, causing a large over-estimation. Here the MLH analysis uses an ALC with very good near range capabilities, i.e. attenuated backscatter profile is usable from the first range gate. The specialised near-range module within the CABAM algorithm (Sect. 2) improves performance in the near range and the evening module addresses the transition between daytime MLH and the new nocturnal layer forming below (Kotthaus and Grimmond, 2018a).

\section{Conclusions}

In cities, where many people are exposed to enhanced pollution emissions, the lack of radiosonde ascents (e.g. due to air traffic control restrictions) make critical ABL volumes poorly known. Thus, improved understanding of the links between atmospheric boundary layer (ABL) dynamics and cloud formation and/or pollution dispersion are of both applied and fundamental interest. With advances in ground-based remote sensing, it becomes increasingly possible to monitor the structure of ABL automatically at high temporal resolutions.

Here, the turbulence-based mixing height (MH) and aerosol-based mixed layer height (MLH) are derived from Doppler lidar and Automatic Lidars and Ceilometers (ALC) profile measurements, respectively. While MH traces the instantaneous process of atmospheric mixing within the ABL, MLH portrays the vertical distribution of aerosol and moisture forming in response. Observations analysed are taken in the highly urbanised setting of central London, UK, during three seasons (autumn, winter and summer) including the ClearfLo measurement campaign (Bohnenstengel et al., 2015a) aiming to shed light on the interactions between air quality and meteorological conditions. Careful data processing and advanced retrieval methods are applied to ensure high quality results.

MLH is derived using the CABAM retrieval method based on attenuated backscatter and cloud base height (CBH) observed with one of the most commonly deployed ALC models (Vaisala CL31). Uncertainty is assessed by comparing fully automatic results to a supervised, semi-automatic detection procedure. While average statistics show hardly any difference with small scatter and a negligible bias, the uncertainty for individual cases can be very high, i.e. in the order of magnitude of the ABL height. Considerable uncertainty is introduced by instrument-specific characteristics that affect the attenuated backscatter profiles. Comparing MLH from supervised detection of one CL31 to fully automatic results based on observations of another sensor of the same make and model running with identical setup and firmware version located at the same site, shows clearly increased deviation for individual time periods. Overall, averages are similar so that the MBE remains very small. Layer attribution uncertainty and instrument-specifics lead to both overand under-estimates that cancel over long periods. Hence, the automatic procedure is considered to provide very reliable results and the between-sensor impacts are assumed negligible if average ABL characteristics are of interest. However, for a small number of cases substantial errors may occur.

MH is derived based on the vertical velocity variance observed with a heterodyne, pulsed Doppler lidar (HALO Photonics) in vertical stare mode. Although very good general agreement is observed between MH obtained from different scan patterns, a systematic effect is found, i.e. a smaller number of velocity observations leads to a greater uncertainty in vertical velocity variance estimates and therefore to higher MH uncertainty.

Doppler lidar and ALC measurements were conducted at several sites in central London (within 3-4 km). To assess if a spatial displacement of such short distances would affect average characteristics of MH and MLH, the layer estimates are compared derived from two Doppler lidars and two ALC located at different sites. While both MH and MLH at the 
different sites generally agree during daytime, the turbulence-derived MH during night might reflect differences in land cover around the sites. However, the systematically lower turbulent activity detected by the Doppler lidar in the more residential neighbourhood does not coincide with a more rapid settling of the ABL aerosol in the area so that nocturnal MLH at both sites is generally in agreement with MH at the denser urban setting. For MLH it is found that the scatter and overall agreement is comparable to results obtained from measurements of the respective sensors operated at the same site. Apart from the nocturnal discrepancy in turbulent exchange and MH, ABL features at the central London sites are very similar or the subtle differences are often not detectable due to the algorithm-, setting- and sensor-related uncertainties. Future studies should evaluate at which spatial scales distinct ABL features form in response to synoptic conditions and land cover characteristics, and are detectable with ground-based remote sensing profilers.

When comparing MH and MLH, a clear response to solar geometry (i.e. time of day and year) and synoptic background in terms of cloud cover and cloud type is apparent. On average, differences between MH and MLH observed in central London during winter, summer and autumn generally agree during night, with median minima being lower for clearskies than for cloudy conditions. While nocturnal values often reflect the same layer, a bias of MH relative to MLH occurs in either direction. In addition to cloud causing strong turbulence signals and gradients in attenuated backscatter, another cause for discrepancy in layer attribution is linked to radiative cooling mechanisms. These lead to an increase in relative humidity which in turn creates gradients in attenuated backscatter through hygroscopic growth of particles rather than in response to dynamical mixing processes. In such situations, different physical processes define the mixing layer and mixed-layer, respectively. Further investigation of such conditions requires detailed profile information of not only atmospheric turbulence but also aerosol concentrations and relative humidity and should hence be addressed in future studies.

MH starts increasing in the morning on average 20-105 min ahead of MLH, presumably because it takes some time for new aerosol gradients to form that can be assigned to MLH. The MH rises up to two times faster than the MLH in cloudy conditions, while growth rates are similar during clear skies. This indicates differences in growth rates might rather be linked to the way the detection algorithms respond to clouds rather than the delayed dispersion of aerosol and moisture. For both MH and MLH daytime maxima increase with day-length and values are highest for convective cloud days following clear-sky nights ( $\mathrm{MH}=1795 \mathrm{~m}$ agl; $\mathrm{MLH}=1409 \mathrm{~m} \mathrm{agl})$ and lowest for stratiform clouds $(\mathrm{MH}$

$=1055 \mathrm{~m} \mathrm{agl} ; \mathrm{MLH}=747 \mathrm{~m} \mathrm{agl}$ ). Daily maximum MH is greater than MLH in most conditions apart from winter clearsky days, with statistics generally more similar in the absence of clouds (median difference of maxima $=100 \mathrm{~m}$ ) and the discrepancy most striking for convective cloud conditions (median difference of maxima $=273 \mathrm{~m}$ ). The disagreement between MH and MLH increases with cloud complexity.

Given MH peaks earlier than MLH, its evening decay phase starts on average about $1 \mathrm{~h}$ ahead. However, MLH has a faster decay rate so the two estimates converge again at around sunset. This finding contradicts some other studies that observe the whole decay period of MLH to be clearly delayed relative to MH or the aerosol-derived layer to not decay at all before sunset. Given the careful data processing and advanced MLH algorithm applied, results obtained in this study are considered more representative of the physical settling process of aerosol layers in response to the decay of turbulent eddies in the evening.

To summarise, $\mathrm{MH}$ and MLH indicate slightly different processes within the ABL. Following very careful data processing (such as the exclusion of profiles with rain or drizzle) and analysis both average characteristics and individual cases are compared. Appropriate flagging of periods affected by rain or decoupled cloud layers is critical to ensure a meaningful comparison. The results show a generally coherent relation between the two, with aerosol characteristics following turbulence signatures with some delay. The findings highlight that turbulence-derived MH and aerosol-derived MLH should not be used inter-changeably for purposes of model evaluation, interpretation of surface air quality observations or initialisation of chemical transport models.

\section{Acknowledgements}

This study and ceilometer and lidar observations have received financial support from EPSRC ACTUAL (EP/G029938/1), EU FP7 BRIDGE, H2020 URBANFLUXES, NERC ClearfLo (NE/H00324X/1 and H003231/1), NERC APHH China AirPro

(NE/N00700X/1), Newton/Met Office CSSP-China, EU COST Action TOPROF ES1303, King's College London and University of Reading. KCL, Royal Geographical Society (with IBG), ERG/LAQN, Imperial College London and Westminster City Council (Steve Neville) are acknowledged for providing site access. We thank all staff and students at KCL and University of Reading who are involved in the LUMO measurement network (ceilometers). We thank Rosy Wilson and John Lally for technical support; and Ewan O'Connor, Guy Pearson and Curtis Wood for technical lidar advice and set-up. We also thank Max Priestman and David Green at ERG for supporting the ceilometer operation.

\section{References}

Atkinson, R.W., Analitis, A., Samoli, E., Fuller, G.W., Green, D.C., Mudway, I.S., Anderson, H.R., Kelly, F.J., 2016. Short-term exposure to traffic-related air pollution and daily mortality in London, UK. J. Expo. Sci. Environ. Epidemiol. 26, $125-132$. doi:10.1038/jes.2015.65

Barlow, J.F., 2014. Progress in observing and modelling the urban boundary layer. Urban Clim. 10, 216-240. doi:10.1016/j.uclim.2014.03.011

Barlow, J.F., Dunbar, T.M., Nemitz, E.G., Wood, C.R., Gallagher, M.W., Davies, F., O’Connor, E., Harrison, R.M., 2011. Boundary layer dynamics over London, UK, as observed using Doppler lidar during REPARTEE-II. Atmos. Chem. Phys. 11, 2111-2125. 
Barlow, J.F., Halios, C.H., Lane, S.E., Wood, C.R., 2015. Observations of urban boundary layer structure during a strong urban heat island event. Environ. Fluid Mech. 15, 373-398. doi:10.1007/s10652-014-9335-6

Bohnenstengel, S.I., Belcher, S.E., Aiken, A., Allan, J.D., Allen, G., Bacak, A., Bannan, T.J., Barlow, J.F., Beddddows, D.C.S., Blossss, W.J., Booth, A.M., Chemel, C., Coceal, O., Di Marco, C.F., Dubey, M.K., Faloon, K.H., Flemiming, Z.L., Furger, M., Gietl, J.K., Graves, R.R., Green, D.C., Grimmimmimmond, C.S.B., Halios, C.H., Hamiamiamilton, J.F., Harrisson, R.M., Heal, M.R., Heard, D.E., Helfter, C., Herndon, S.C., Holmes, R.E., Hopkins, J.R., Jones, A.M., Kelly, F.J., Kotthaus, S., Langford, B., Lee, J.D., Leigh, R.J., Lewisis, A.C., Lidsidsidster, R.T., Lopez-Hilfiker, F.D., McQuaidaid, J.B., Mohr, C., Monks, P.S., Nemimitz, E., Ng, N.L., Percival, C.J., Prévôt, A.S.H., Ricketts, H.M.A., Sokhi, R., Stone, D., Thornton, J.A., Tremper, A.H., Valach, A.C., Vissississer, S., Whalley, L.K., Williamsiamsiamsiams, L.R., Xu, L., Young, D.E., Zotter, P., 2015a. Meteorology, air quality, and health in London: The ClearfLo project. Bull. Am. Meteorol. Soc. 96, 779-804. doi:10.1175/BAMS-D-1200245.1

Bohnenstengel, S.I., Evans, S., Clark, P.A., Belcher, S.E., 2011. Simulations of the London urban heat island. Quart. J. R. Met. Soc. 137, 1625-1640. doi:10.1002/qj.855

Bohnenstengel, S.I., Hamilton, I., Davies, M., Belcher, S.E., 2014. Impact of anthropogenic heat emissions on London's temperatures. Q. J. R. Meteorol. Soc. 140, 687-698. doi:10.1002/qj.2144

Bohnenstengel, S.I., Kotthaus, S., Barlow, J., Grimmond, S., Coceal, O., Lean, H., Lee, J., Tremper, A., Crilley, L., Green, D., Halios, C., Belcher, S., 2015b. Bohnenstengel, S, S Kotthaus, et al.: The ClearflO project - Are sea breezes a mechanism to change the air in London?, in: ICUC9. Toulouse, p. 20-24 July 2015.

Bonin, T.A., Choukulkar, A., Brewer, W.A., Sandberg, S.P., Weickmann, A.M., Pichugina, Y.L., Banta, R.M., Oncley, S.P., Wolfe, D.E., 2017. Evaluation of turbulence measurement techniques from a single Doppler lidar. Atmos. Meas. Tech. 10, $3021-3039$. doi:10.5194/amt-10-3021-2017

Curci, G., Ferrero, L., Tuccella, P., Barnaba, F., Angelini, F., Bolzacchini, E., Carbone, C., Denier van der Gon, H.A.C., Facchini, M.C., Gobbi, G.P., Kuenen, J.P.P., Landi, T.C., Perrino, C., Perrone, M.G., Sangiorgi, G., Stocchi, P., 2015. How much is particulate matter near the ground influenced by upper-level processes within and above the PBL? A summertime case study in Milan (Italy) evidences the distinctive role of nitrate. Atmos. Chem. Phys. 15, 2629-2649. doi:10.5194/acp-15-2629-2015

Gabey, A.M., Grimmond, C.S.B., Capel-Timms, I., 2018. Anthropogenic Heat Flux: Advisable spatial resolutions when input data are scarce. Theor. Appl. Clim. doi:10.1007/s00704-018-2367-y

Geiß, A., Wiegner, M., Bonn, B., Schäfer, K., Forkel, R., von Schneidemesser, E., Münkel, C., Chan, K.L., Nothard, R., 2017. Mixing layer height as an indicator for urban air quality? Atmos. Meas. Tech. 10, 2969-2988. doi:10.5194/amt-10-2969-2017

Gibert, F., Cuesta, J., Yano, J.-I., Arnault, N., Flamant, P.H., 2007. On the Correlation between Convective Plume Updrafts and Downdrafts, Lidar Reflectivity and Depolarization Ratio. Boundary-Layer Meteorol. 125, 553-573. doi:10.1007/s10546-0079205-6

Haeffelin, M., Angelini, F., Morille, Y., Martucci, G., Frey, S., Gobbi, G.P., Lolli, S., O’Dowd, C.D., Sauvage, L., Xueref-Rémy, I., Wastine, B., Feist, D.G., 2012. Evaluation of Mixing-Height Retrievals from Automatic Profiling Lidars and Ceilometers in View of Future Integrated Networks in Europe. Boundary-Layer Meteorol. 143, 49-75. doi:10.1007/s10546-011-9643-z

Haeffelin, M., Laffineur, Q., Bravo-Aranda, J.-A., Drouin, M.-A., Casquero-Vera, J.-A., Dupont, J.-C., De Backer, H., 2016. Radiation fog formation alerts using attenuated backscatter power from automatic lidars and ceilometers. Atmos. Meas. Tech 9, 5347-5365. doi:10.5194/amt-9-5347-2016

Halios, C.H., Barlow, J.F., 2017. Observations of the Morning Development of the Urban Boundary Layer Over London, UK, Taken During the ACTUAL Project. Boundary-Layer Meteorol. 1-28. doi:10.1007/s10546-017-0300-Z

Haman, C.L., Lefer, B., Morris, G.A., Haman, C.L., Lefer, B., Morris, G.A., 2012. Seasonal Variability in the Diurnal Evolution of the Boundary Layer in a Near-Coastal Urban Environment. J. Atmos. Ocean. Technol. 29, 697-710. doi:10.1175/JTECH-D-1100114.1

Harrison, R.M., 2017. Urban atmospheric chemistry: a very special case for study. npj Clim. Atmos. Sci. 1, 5. doi:10.1038/s41612017-0010-8

Harrison, R.M., Dall'Osto, M., Beddows, D.C.S., Thorpe, A.J., Bloss, W.J., Allan, J.D., Coe, H., Dorsey, J.R., Gallagher, M., Martin, C., Whitehead, J., Williams, P.I., Jones, R.L., Langridge, J.M., Benton, A.K., Ball, S.M., Langford, B., Hewitt, C.N., Davison, B., Martin, D., Petersson, K.F., Henshaw, S.J., White, I.R., Shallcross, D.E., Barlow, J.F., Dunbar, T., Davies, F., Nemitz, E., Phillips, G.J., Helfter, C., Di Marco, C.F., Smith, S., 2012. Atmospheric chemistry and physics in the atmosphere of a developed megacity (London): an overview of the REPARTEE experiment and its conclusions. Atmos. Chem. Phys. 12, 3065-3114. doi: $10.5194 /$ acp-12-3065-2012

Harvey, N.J., Hogan, R.J., Dacre, H.F., 2015. Evaluation of boundary-layer type in a weather forecast model utilizing long-term Doppler lidar observations. Q. J. R. Meteorol. Soc. 141, 1345-1353. doi:10.1002/qj.2444

Hervo, M., Poltera, Y., Haefele, A., 2016. An empirical method to correct for temperature dependent variations in the overlap function of CHM15k ceilometers. Atmos. Meas. Tech. Discuss. 1-27. doi:10.5194/amt-2016-30

Hirsikko, A., O’Connor, E.J., Komppula, M., Korhonen, K., Pfüller, A., Giannakaki, E., Wood, C.R., Bauer-Pfundstein, M., Poikonen, A., Karppinen, T., Lonka, H., Kurri, M., Heinonen, J., Moisseev, D., Asmi, E., Aaltonen, V., Nordbo, A., Rodriguez, E., Lihavainen, H., Laaksonen, A., Lehtinen, K.E.J., Laurila, T., Petäjä, T., Kulmala, M., Viisanen, Y., 2014. Observing wind, aerosol particles, cloud and precipitation: Finland's new ground-based remote-sensing network. Atmos. Meas. Tech. 7, 13511375. doi:10.5194/amt-7-1351-2014

Hogan, R.J., Grant, A.L.M., Illingworth, A.J., Pearson, G.N., O’Connor, E.J., 2009. Vertical velocity variance and skewness in clear and cloud-topped boundary layers as revealed by Doppler lidar. Q. J. R. Meteorol. Soc. 135, 635-643. doi:10.1002/qj.413

Kent, C.W., Grimmond, S., Barlow, J., Gatey, D., Kotthaus, S., Lindberg, F., Halios, C.H., 2017. Evaluation of Urban Local-Scale Aerodynamic Parameters: Implications for the Vertical Profile of Wind Speed and for Source Areas. Boundary-Layer Meteorol. 164, 183-213. doi:10.1007/s10546-017-0248-z

Kotthaus, S., Grimmond, C.S.B., 2018a. Atmospheric Boundary Layer Characteristics from Ceilometer measurements, Part 1: A new method to track mixed layer height and classify clouds, in review.

Kotthaus, S., Grimmond, C.S.B., 2018b. Atmospheric Boundary Layer Characteristics from Ceilometer measurements, Part 2: Application to London's Urban Boundary Layer, in review 
Kotthaus, S., Grimmond, C.S.B., 2014. Energy exchange in a dense urban environment - Part I: Temporal variability of long-term observations in central London. Urban Clim. 10, 261-280. doi:10.1016/j.uclim.2013.10.002

Kotthaus, S., O’Connor, E., Münkel, C., Charlton-Perez, C., Haeffelin, M., Gabey, A.M., Grimmond, C.S.B., 2016. Recommendations for processing atmospheric attenuated backscatter profiles from Vaisala CL31 ceilometers. Atmos. Meas. Tech. 9, 3769-3791. doi:10.5194/amt-9-3769-2016

Lelieveld, J., Evans, J.S., Fnais, M., Giannadaki, D., Pozzer, A., 2015. The contribution of outdoor air pollution sources to premature mortality on a global scale. Nature 525, 367-371. doi:10.1038/nature15371

Lindberg, F., Grimmond, C., Yogeswaran, N., Kotthaus, S., He, J., Allen, L., Iamarino, M., 2013. Impact of urban changes and weather on anthropogenic heat flux in Europe 1995-2015. Urban Clim. 4, 1-15. doi:http://dx.doi.org/10.1016/j.uclim.2013.03.002

Morille, Y., Haeffelin, M., Drobinski, P., Pelon, J., 2007. STRAT: An Automated Algorithm to Retrieve the Vertical Structure of the Atmosphere from Single-Channel Lidar Data. J. Atmos. Ocean. Technol. 24, 761-775. doi:10.1175/JTECH2008.1

Pal, S., Haeffelin, M., 2015. Forcing mechanisms governing diurnal, seasonal, and interannual variability in the boundary layer depths: Five years of continuous lidar observations over a suburban site near Paris. J. Geophys. Res. 120, 11,936-11,956. doi:10.1002/2015JD023268

Pearson, G., Davies, F., Collier, C., 2010. Remote sensing of the tropical rain forest boundary layer using pulsed Doppler lidar. Atmos. Chem. Phys. 10, 5891-5901. doi:10.5194/acp-10-5891-2010

Piringer, M., Joffre, S., Baklanov, A., Christen, A., Deserti, M., Ridder, K., Emeis, S., Mestayer, P., Tombrou, M., Middleton, D., Baumann-Stanzer, K., Dandou, A., Karppinen, A., Burzynski, J., 2007. The surface energy balance and the mixing height in urban areas-activities and recommendations of COST-Action 715. Boundary-Layer Meteorol. 124, 3-24. doi:10.1007/s10546007-9170-0

Randriamiarisoa, H., Chazette, P., Couvert, P., Sanak, J., Mégie, G., 2006. Relative humidity impact on aerosol parameters in a Paris suburban area. Atmos. Chem. Phys. 6, 1389-1407. doi:10.5194/acp-6-1389-2006

Schween, J.H., Hirsikko, A., Löhnert, U., Crewell, S., 2014. Mixing-layer height retrieval with ceilometer and Doppler lidar: from case studies to long-term assessment. Atmos. Meas. Tech. 7, 3685-3704. doi:10.5194/amt-7-3685-2014

Seibert, P., 2000. Review and intercomparison of operational methods for the determination of the mixing height. Atmos. Environ. 34, 1001-1027. doi:10.1016/S1352-2310(99)00349-0

Spanton, A.M., Williams, M.L., 1988. A comparison of the structure of the atmospheric boundary layers in Central London and a rural/suburban site using acoustic sounding. Atmos. Environ. 22, 211-223. doi:10.1016/0004-6981(88)90029-7

Statistics, O. for N., 2017. Population Estimates for UK, England and Wales, Scotland and Northern Ireland: Mid-2016.

Stull, R.B., 1988. An Introduction to Boundary Layer Meteorology, Kluwer Academic Publishers Group, Dordrecht. Kluwer Acad. Publ., Dordrecht. doi:10.1007/978-94-009-3027-8

Sujatha, P., Mahalakshmi, D. V, Ramiz, A., Rao, P.V.N., Naidu, C. V, 2016. Ventilation coefficient and boundary layer height impact on urban air quality. Cogent Environ. Sci. 2. doi:10.1080/23311843.2015.1125284

Sun, T., Kotthaus, S., Li, D., Ward, H.C., Gao, Z., Ni, G., Grimmond, S., 2017. Attribution and mitigation of heat wave-induced urban heat storage change. Environ. Res. Lett. doi:10.1088/1748-9326/aa922a

Tang, G., Zhang, J., Zhu, X., Song, T., Münkel, C., Hu, B., Schäfer, K., Liu, Z., Zhang, J., Wang, L., Xin, J., Suppan, P., Wang, Y., 2016. Mixing layer height and its implications for air pollution over Beijing, China. Atmos. Chem. Phys. 16, 2459-2475. doi:10.5194/acp-16-2459-2016

Träumner, K., Kottmeier, C., Corsmeier, U., Wieser, A., 2011. Convective Boundary-Layer Entrainment: Short Review and Progress using Doppler Lidar. Boundary-Layer Meteorol. 141, 369-391. doi:10.1007/s10546-011-9657-6

Visser, S., Slowik, J.G., Furger, M., Zotter, P., Bukowiecki, N., Dressler, R., Flechsig, U., Appel, K., Green, D.C., Tremper, A.H., Young, D.E., Williams, P.I., Allan, J.D., Herndon, S.C., Williams, L.R., Mohr, C., Xu, L., Ng, N.L., Detournay, A., Barlow, J.F., Halios, C.H., Fleming, Z.L., Baltensperger, U., Prévôt, A.S.H., 2015. Kerb and urban increment of highly time-resolved trace elements in PM10, PM2.5 and PM1.0 winter aerosol in London during ClearfLo 2012. Atmos. Chem. Phys. 15, $2367-2386$. doi:10.5194/acp-15-2367-2015

Ward, H.C., Kotthaus, S., Grimmond, C.S.B., Bjorkegren, A., Wilkinson, M., Morrison, W.T.J., Evans, J.G., Morison, J.I.L., Iamarino, M., 2015. Effects of urban density on carbon dioxide exchanges: Observations of dense urban, suburban and woodland areas of southern England. Environ. Pollut. 198, 186-200. doi:10.1016/j.envpol.2014.12.031

Warren, E., Charlton-Perez, C., Kotthaus, S., Lean, H., Ballard, S., Hopkin, E., Grimmond, S., 2018. Evaluation of forward-modelled attenuated backscatter using an urban ceilometer network in London under clear-sky conditions. Atmos. Environ.

Wiegner, M., Emeis, S., Freudenthaler, V., Heese, B., Junkermann, W., Münkel, C., Schäfer, K., Seefeldner, M., Vogt, S., 2006. Mixing layer height over Munich, Germany: Variability and comparisons of different methodologies. J. Geophys. Res. 111, D13201. doi:10.1029/2005JD006593

Wood, C.R., Lacser, A., Barlow, J.F., Padhra, A., Belcher, S.E., Nemitz, E., Helfter, C., Famulari, D., Grimmond, C.S.B., 2010. Turbulent Flow at 190 m Height Above London During 2006-2008: A Climatology and the Applicability of Similarity Theory. Bound. Lay. Met. 137, 77-96.

Wouters, H., De Ridder, K., Demuzere, M., Lauwaet, D., van Lipzig, N.P.M., 2013. The diurnal evolution of the urban heat island of Paris: a model-based case study during Summer 2006. Atmos. Chem. Phys. 13, 8525-8541. doi:10.5194/acp-13-8525-2013 


\section{Supplemental material}

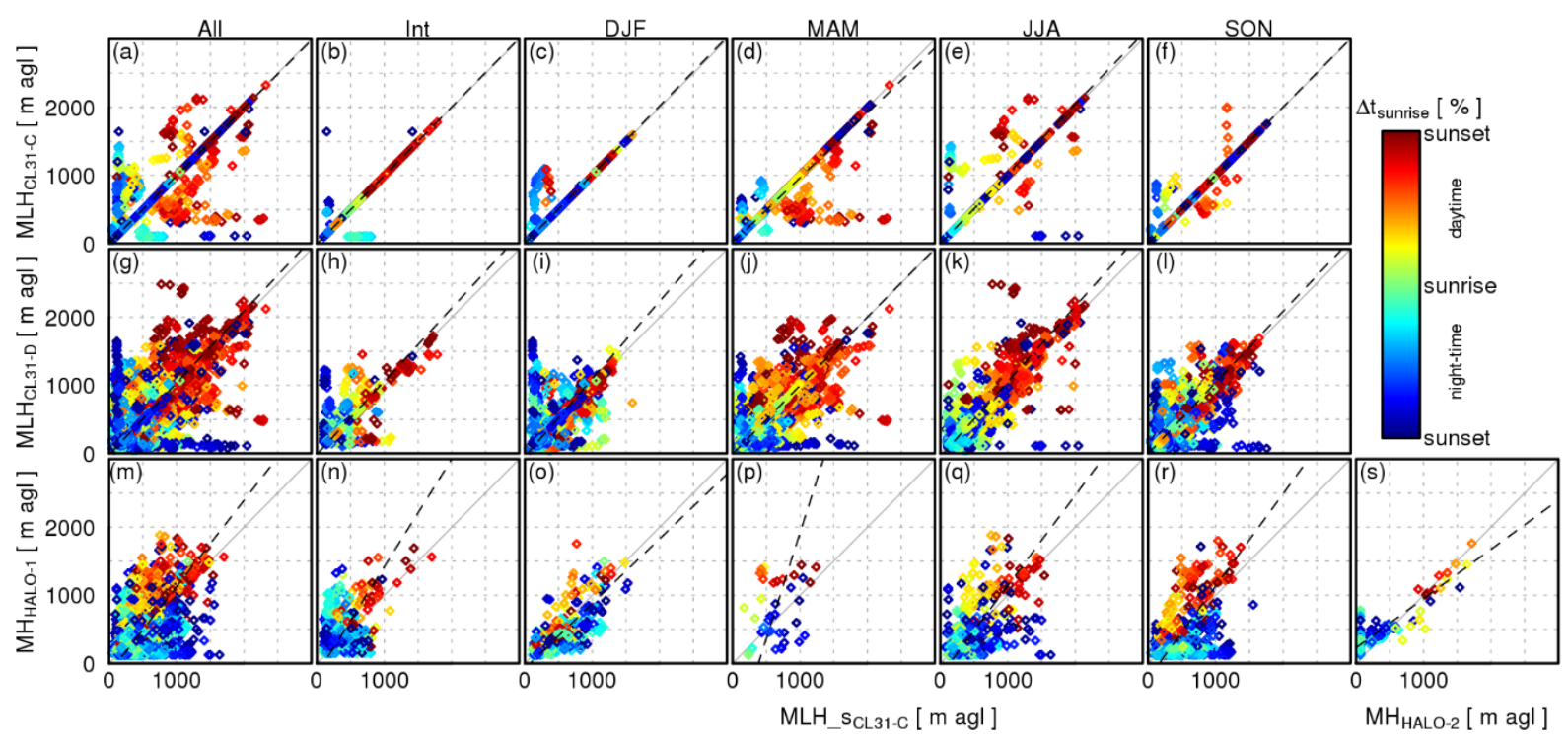

Figure S.1: Same as Figure 2 but restricted to cloud-free conditions: Turbulence-derived MH from Doppler lidar HALO-1 (m-r) and aerosol-derived MLH from two ALC (CL31-C (a-f) and CL31-D (g-l)) against aerosol-derived MLH from CL31-C including supervised layer selection for $(a, g, m)$ all data available in 10/2010-12/2012, $(b, h, n)$ the inter-comparison period with all three sensors located at KCL (Table 2), and times with HALO-1 at WCC, CL31-C at MR andCL31-D at NK separated by season: (c, i, o) winter, (d, j, p) spring, $(e, k, q)$ summer, and ( $f, l, r)$ autumn; (s) shows comparison of MH from HALO-1 at WCC against HALO-2 at NK. Colours indicate time relative to sunrise. Selection restricted to times when no clouds are detected by either ALC below $3000 \mathrm{~m}$. (dashed line) linear relation with slope and intercept given in Table 3; (solid line) 1:1 line.

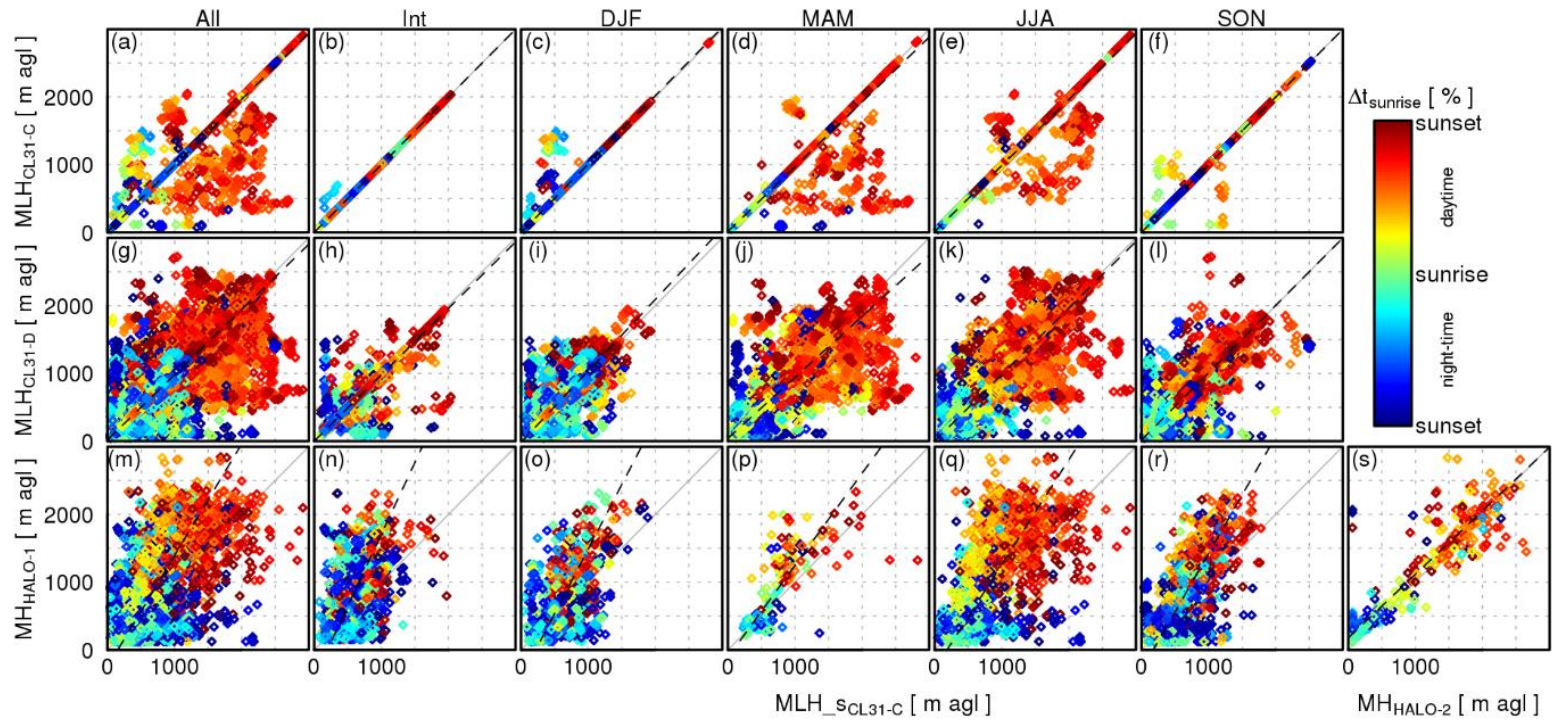

Figure S.2: Same as Figure 2 but restricted to cloudy conditions: Turbulence-derived MH from Doppler lidar HALO-1 (m-r) and aerosolderived MLH from two ALC (CL31-C (a-f) and CL31-D (g-l)) against aerosol-derived MLH from CL31-C including supervised layer selection for $(a, g, m)$ all data available in 10/2010 - 12/2012, $(b, h, n)$ the inter-comparison period with all three sensors located at KCL (Table 2), and times with HALO-1 at WCC, CL31-C at MR andCL31-D at NK separated by season: (c, i, o) winter, (d, j, p) spring, (e, $k, q)$ summer, and ( $f, l, r)$ autumn; (s) shows comparison of MH from HALO-1 at WCC against HALO-2 at NK. Colours indicate time relative to sunrise. Selection restricted to times when clouds are detected by either ALC below $3000 \mathrm{~m}$. (dashed line) linear relation with slope and intercept given in Table 3; (solid line) 1:1 line. 


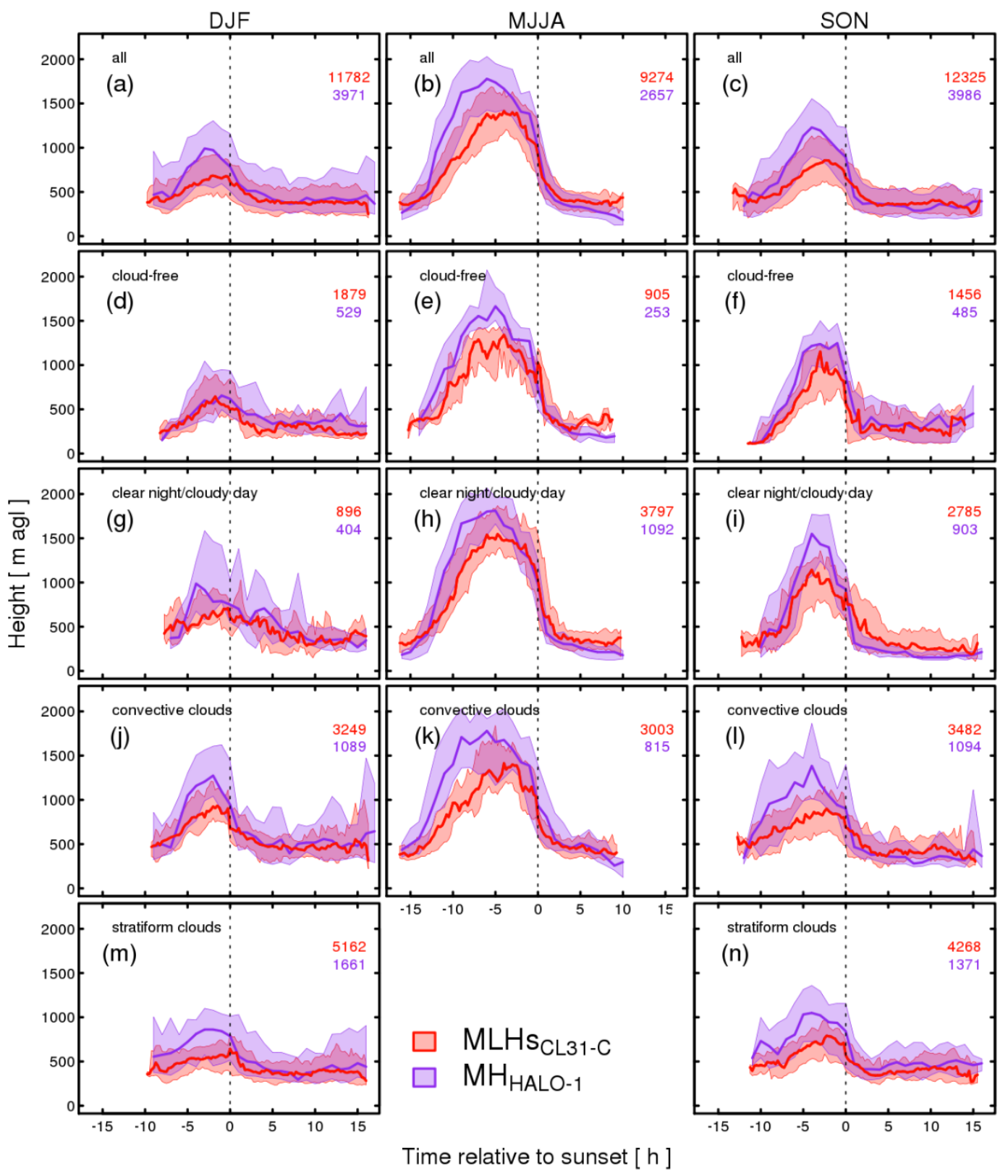

Figure S.3: Median diurnal pattern with inter-quartile range (shading) of turbulence-derived $\mathrm{MH}$ (1 h and $30 \mathrm{~min}$ resolution during night and day, respectively) from Doppler lidar and aerosol-derived MLH (15 min) from ALC against time relative to sunset for (a-c) all days with both HALO-1 and CL31-C data available and separated into (d-f) cloudfree conditions, (g-i) clear nights followed by cloudy days, (j-1) convective cloud conditions, and (m, $n$ ) stratiform cloud conditions. Columns separate days by season: (a, d, g, j, m) winter, (b, e, h, k) May and summer, and (c, f, I, l, n) autumn, respectively. ABL classification according to CABAM results (Sect. 2). Number of available data points are listed in each subplot. Figure 7 is centred on sunrise. 